\title{
Protocolo técnico para la fotografía de fuentes filológicas primarias
}

\author{
Ricardo Guixà, Alberto Montaner \\ Universitat de Barcelona, Universidad de Zaragoza \\ rguixa@ub.edu, http://orcid.org/oooo-oooI-5I52-3504 \\ amonta@unizar.es, http://orcid.org/oooo-00O2-4906-4246 \\ Rebut 28/O2/2OI4; acceptat 25/o6/20I4 \\ DOI Io.7203/MCLM.I.3369
}

\section{A technical protocol for photography of philological primary sources}

\begin{abstract}
This paper presents a technical protocol for taking photographs of primary sources of philological use for documentary purposes. The protocol is designed for obtaining an image as close to the original object as possible. The first section provides a detailed description of the materials necessary for photographing handwritten or printed texts. The next section describes a method adapted to the new circumstances of digital photography, in two steps: capturing RAW images, then editing them. This study gives a systematic description of the first part, describing, step by step, the technical decisions related to photographic shot settings in different lighting situations, with the aims of maximizing the quality of the result and preventing any loss of relevant data.
\end{abstract}

KEYWORDS

Technical protocol for photography; photography of primary sources; manuscripts; digital cameras; capturing raw format images; photographic settings; lighting.

\section{b*}

RESUMEN

Este artículo propone un protocolo técnico orientado a la obtención de fotografías de fuentes primarias de uso filológico con fines documentales, proyectado para garantizar la máxima fidelidad posible al motivo original representado. Tras una descripción detallada del material necesario, seleccionado específicamente en función de las necesidades particulares de la fotografía de textos manuscritos o impresos, se desarrolla un procedimiento adaptado a las nuevas circunstancias de la fotografía digital, concebido en dos fases: la captación de la imagen en formato RAW, y su posterior edición. En este estudio se trata la primera parte, describiendo sistemáticamente, paso a paso, las decisiones técnicas relativas a los ajustes fotográficos de la toma en diferentes situaciones lumínicas, encaminadas a maximizar la calidad de la imagen resultante y evitar cualquier pérdida de información.

\section{Palabras clave}

Protocolo técnico fotográfico; fotografía de fuentes primarias; manuscritos; cámara digital; captura de imágenes, formato RAW; ajustes fotográficos; iluminación.

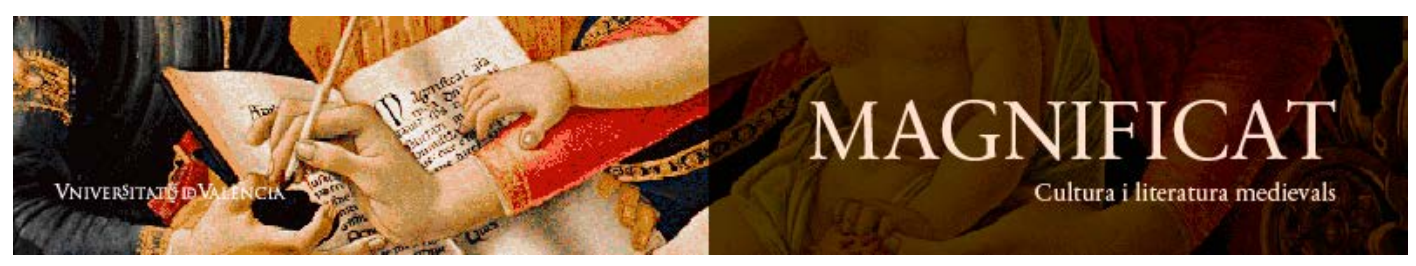

Magnificat Cultura i Literatura Medievals I, 20I4, 5I-88. http://ojs.uv.es/index.php/MCLM

ISSN 2386-8295 
El presente trabajo se inscribe en las actividades del Proyecto del Plan Nacional de I+D+i del Ministerio de Economía y Competitividad FFI20I2-3223r: Formas de la Épica Hispánica: Tradiciones y Contextos Históricos II.

Ricardo Guixà i Alberto Montaner, "Protocolo técnico para la fotografía de fuentes filológicas primarias”, Magnificat Cultura i Literatura Medievals I, 20I4, 5 $5^{\mathrm{I}-88 .(\mathrm{cc}) \mathrm{BV}}$

\section{TABLA DE CONTENIDOS}

I Introducción - 53

${ }_{2}$ Objetivo -54

3 Equipamiento fotográfico -55

3.I Cámara - 55

3.I.I Visor óptico - 55

3.I.2 Tamaño y peso -55

3.I.3 Lentes $-5^{6}$

3.I.4 RAW - 57

3.I.5 Calidad de imagen - 57

3.I.5.I La resolución -57

3.I.5.2 La profundidad de color -57

3.I.5.3 El ruido $-5^{8}$

3.I.5.4 El rango dinámico $-5^{8}$

$3 \cdot 2$ Soportes - 59

3.3 Iluminación - 62

3.4 Fotómetro y carta de gris medio - 64

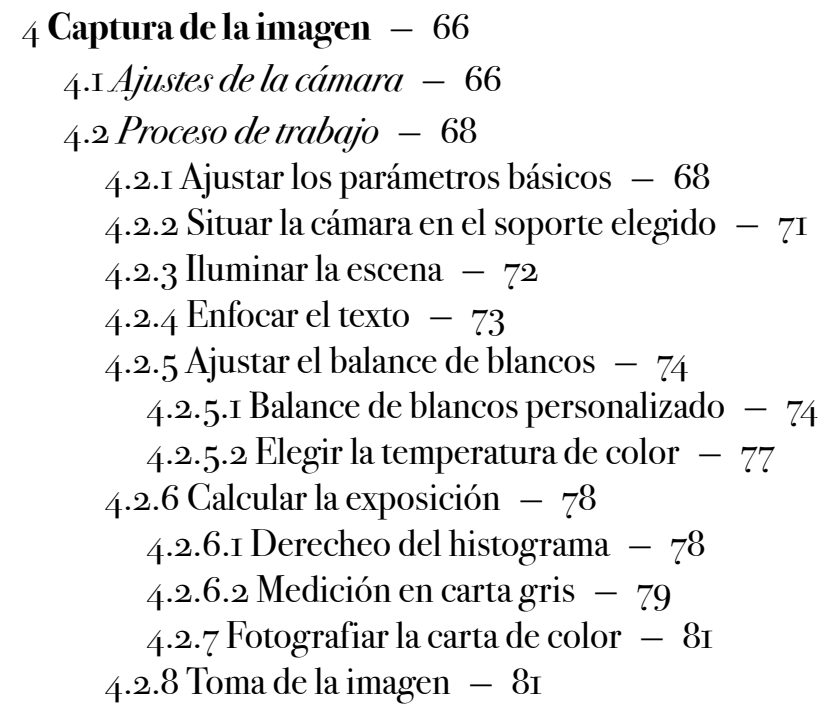

5 Protocolo en condiciones de precariedad de medios -82

5.I Configuración de la cámara - 82

5.2 Proceso de trabajo - 82

6 Anexos - 85

6.I Glosario - 85

6.2 Acrónimos - 87

${ }_{7}$ Obras citadas -87 


\section{$\partial * \approx$}

\section{Introducción}

$\mathrm{E}$ presente artículo, primero de una serie destinada a exponer los recursos fotográficos de los que se puede valer el filólogo para afrontar el estudio de las fuentes primarias (especialmente, pero no solo, las más distantes en el tiempo), nace de las necesidades advertidas durante el trabajo de campo vinculado a las actividades de tres sucesivos Proyectos de Investigación: HUM2005-05783: Génesis y Evolución de la Materia Cidiana en la Edad Media y el Siglo de Oro (2005-2008), FFI2009-I3058: Formas de la Épica Hispánica: Tradiciones y Contextos Históricos (2010-2OI2) y IFFI2OI2-3223I: Formas de la Épica Hispánica: Tradiciones y Contextos Históricos II (2OI320I5). En sus respectivas memorias técnicas se especificaba que uno de sus objetivos primordiales radicaba en la digitalización y restauración virtual, con transcripción cuasifacsimilar y comentario paleográfico y ecdótico, de testimonios épicos o materiales conexos de difícil legibilidad. ${ }^{\mathrm{I}}$ Para ello se contaba especialmente con el empleo de la fotografía de análisis hiperespectral (Montaner 2008 y 2009), lo cual resultaba posible por tener a nuestra disposición la cámara Musis HS adquirida por la Universidad de Zaragoza con ocasión de su participación en un proyecto anterior, el European Project Rinascimento virtuale (RV) - Digitale Palimpsestforschung, ${ }^{2}$ cuyo director por parte española era el profesor Ángel Escobar, miembro también de los tres Proyectos precitados.

Sin embargo, las tareas de documentación anejas a esta labor exigían disponer también de fotografías digitales de alta resolución ( $c f$. Montaner 2009, 266, 27 , 273) y, por otro lado, otros equipos de investigación que se enfrentaban a documentos con problemas de legibilidad no disponían de dicho aparato, relativamente costoso para los presupuestos habituales de los proyectos de investigación en Humanidades. Esto se ha resuelto en ocasiones mediante una fructífera colaboración de nuestro grupo de investigadores con otros que han solicitado nuestra colaboración, ${ }^{3}$ pero esta, por razones diversas, no siempre resulta posible. A cambio, a partir de unas fotografías bien realizadas, los problemas menos graves de este tipo pueden resolverse en la posproducción de las mismas. Todo ello nos hizo pensar en la conveniencia de elaborar un protocolo técnico que permitiese a cualquier filólogo (y, para el caso, a cualquier estudioso enfrentado a este tipo de materiales) con una mínima formación fotográfica realizar una labor adecuada de documentación fotográfica sobre las fuentes primarias objeto de estudio. Para ello, contábamos con el conocimiento directo de las necesidades de un investigador en este campo y su especial problemática, experimentadas por diversos miembros del Proyecto, por un lado, y por otro, con los conocimientos técnicos de un fotógrafo especializado en el ámbito de la fotografía científica y sus

I. Las memorias técnicas iniciales, así como las de resultados, de FFI2Oo9-I3O58 y FFI2OI2-3223I están accesibles en línea en https://unizar.academia.edu/FEHTYCH.

2. Sobre sus actividades puede verse su página web http://www.rinascimentovirtuale.eu/.

3. Citaremos, por poner dos ejemplos, las sesiones de trabajo mantenidas los días i2 y 22 de marzo de 20 o en la Biblioteca de la Universidad de Zaragoza, en colaboración con el Équipe d'accueil 4083 de la Sorbona, Civilisations et Littératures d'Espagne et d'Amérique du Moyen-Âge aux Lumières, en el marco de AILP GDRE 67I du CNRS: Groupement de Recherche Européen "Approche interdisciplinaire des logiques de pouvoir dans les sociétés ibériques médiévales", para examinar el Codex Villarensis (ms. BUZ 225), que contiene el testimonio más antiguo del Liber regum, entre otros materiales (véase la figura 38), así como el examen de fondos pertenecientes a la sección de reserva manuscrita de la Biblioteca de la Universidad de Barcelona y al archivo de la Parroquia de Caldes de Montbui, realizado los días 8 y 9 de mayo de 20I3, en colaboración con el Proyecto FFI2OII-28719-Co2-ol BITECA 2.o: Del libro medieval a Internet en la Corona de Aragón: BITECA (textos catalanes). 
requisitos. ${ }^{4} \mathrm{El}$ resultado de esta colaboración son las páginas que siguen, primera entrega de la que confiamos sea una serie completa de artículos que permitan atender a todos los aspectos del proceso y a la mayor parte de su casuística.

\section{${ }_{2}$ Objetivo}

Las fuentes primarias para uso filológico son los textos e inscripciones manuscritas o impresas, antiguas o modernas, que emplean los estudiosos de la literatura y el lenguaje como base de sus investigaciones. El soporte más habitual de estas manifestaciones escritas es el papel, el pergamino y, con menos frecuencia, el papiro. Aunque también hay que considerar las fuentes epigráficas sobre material rígido como la piedra, el bronce, el marfil o el hueso, estas suelen tener mayor relevancia histórica que literaria, aunque obviamente también puedan poseerla (piénsese en los carmina latina epigraphica que editó Bücheler I895-1897, por poner solo un ejemplo notorio), además de presentar una problemática diferente en punto a la adecuada captación de imágenes.

Por lo general, debido a su valor histórico-cultural y a la fragilidad de este tipo de documentos, particularmente aquellos sobre soporte flexible, los manuscritos no se pueden sacar de su lugar de conservación, por lo que el investigador se ve obligado a realizar fotografías para poder estudiarlos con mayor detenimiento. ${ }^{5}$ Estas imágenes de carácter científico deben garantizar la mayor fidelidad posible al original, y conllevan una serie de dificultades específicas asociadas a la naturaleza de la superficie fotografiada y a las necesidades implícitas al trabajo del filólogo que complican esta tarea a cualquier fotógrafo inexperto, ya que implican una serie de operaciones técnicas en las que se requiere un conocimiento especializado destinado a optimizar el resultado. ${ }^{6}$ Por otro lado, con la aparición de la fotografía digital, los parámetros que permiten ejercer el control sobre la imagen resultante se han vuelto más numerosos y complejos, incrementando así el grado de dificultad de cada toma.

Este protocolo se propone dotar al filólogo de un método de trabajo que le permita realizar este género de fotografías con una calidad profesional y está orientado a obtener el máximo de información de los textos documentados con la mínima distorsión posible en diferentes tipos de situaciones. ${ }^{7}$ Constará de tres secciones:

4. Conste, por tanto, que, aunque Alberto Montaner figure como autor secundario, por su colaboración en la concepción general del artículo y en su plan de trabajo, la redacción del mismo se debe casi enteramente a Ricardo Guixà.

5. En la actualidad existen dos procedimientos que permiten una reproducción fotomecánica de documentos: el escáner y la cámara fotográfica. En el caso de las fuentes primarias la primera opción tiene el inconveniente de que puede resultar perjudicial para su conservación, tal y como señala Michael J. Leclerc: "Scanning is a good way to create a digital image of flat papers and images. However, be aware that the bright light created by the scanner can do damage to originals. Documents that are in fragile condition, with faded writing, should not be scanned. The bright light can cause even more fading. If they must be scanned, you must be certain to scan them as few times as possible. Every time the image is exposed to the bright light, you are causing damage. Sometimes the damage is not visible to the naked eye, but it will eventually show up in the document" (Leclerc 2OIO).

6. La aparición de la tecnología digital ha supuesto una verdadera revolución en el campo de la reproducción de materiales para la investigación, que prácticamente no había evolucionado desde el primer tercio del siglo XX, como se puede comprobar en el manual de Robert C Binkley (I93I), titulado Methods of reproducing research materials. Para el paso de las viejas a las nuevas tecnologías en este terreno, véase Faraggiana di Sarzana (2003 y 2007).

7. Como constata Yves Le Guillou, la reproducción fotomecánica nace con la propia fotografía: “L'histoire de la reproduction des documents graphiques commence véritablement en I826. Cette année-là, Niépce met au point, sans le savoir, l'ensemble de la chaîne graphique en inventant un procédé de restitution de l'image: l'héliographie, et un procédé de restitution de l'image: l'héliogravure" (Le Guillou 2008, 3). Sustituyendo al grabado en los libros, los productos de la cámara transfirieron a las imágenes obtenidas toda la carga epistemológica asociada a su origen tecnológico y a la 
I. El primero está dedicado a explicar el material necesario y el procedimiento adecuado para hacer las fotografías, centrándose en el proceso de realización de la imagen, e incluye un apéndice sobre el procedimiento a seguir en condiciones precarias de medios técnicos.

2. El segundo tratará sobre la edición digital con Photoshop de las representaciones obtenidas y estará especialmente orientado a visibilizar el texto objeto de estudio cuando presente defecto de legibilidad.

3. En el tercero se explicarán los procedimientos adecuados para situaciones específicas como la fotografía de textos con superficies reflectantes o la fotografía de detalles y filacterias.

En el presente artículo se abordará solo la primera sección, dejando los siguientes para escritos posteriores, debido a su propia complejidad y (sobre todo en el segundo punto) al empleo de otro tipo de técnicas. Al final de esta primera entrega se ofrece un anexo con un glosario de términos específicos de la nomenclatura fotográfica y una lista de los acrónimos empleados en la misma.

\section{Equipamiento fotográfico}

3.I Cámara

En la actualidad el mercado nos ofrece una gran variedad de cámaras con diferentes características. Lo primero que conviene aclarar es que no existe un modelo o marca ideal; todo depende de las necesidades del fotógrafo que la vaya a utilizar. En el caso del filólogo, la cámara recomendada sería una réflex digital por varias razones de peso:

I. Facilidad para encuadrar y enfocar con su visor óptico. Algunos modelos disponen de pantallas abatibles que también pueden resultar útiles en esta labor.

2. Tamaño y peso adecuados para ser transportada sin dificultad, con una equilibrada relación calidad / precio.

3. Gran variedad de ópticas que permiten adaptarnos a las diferentes necesidad de la toma

4. Capacidad para generar archivos RAW.

5. Mayor resolución y rango dinámico de la imagen, con un nivel de ruido inferior.

Veamos estas características con mayor detenimiento.

\section{I.I Visor óptico}

El visor de una cámara réflex muestra a través de un mecanismo compuesto por un espejo y un prisma pentagonal (pentaprisma) la imagen proporcionada directamente por la lente, la misma que se proyecta en el sensor digital. Gracias a este sistema se puede realizar un encuadre con alta precisión al mismo tiempo que facilita el enfoque directo, sin mediación de pantallas electrónicas. Por otro lado, aquellos modelos que disponen de una pantalla TFT abatible y un sistema de visionado directo a través de ella (Live view) simplifican el trabajo de encuadre cuando la cámara se encuentra en el trípode o una mesa de reproducciones.

$$
\text { 3.I.2 Tamaño y peso }
$$

Inevitablemente una cámara réflex es siempre más grande y pesada que una cámara compacta o

particular relación con lo real. "C'est la photographie qui donne à l'illustration son caractère 'scientifique', incontestable” (Le Guillou 2008, 4), 
una CSC, porque necesita espacio en su interior para situar el espejo y el prisma que la define; sin embargo, sigue manteniendo unas medidas adecuadas para el transporte, con una calidad y prestaciones que compensan sobradamente sus inconvenientes.

En una cámara digital, el sensor electrónico que captura la imagen no tiene un tamaño estándar y universal. Los formatos más extendidos en las cámaras réflex actuales son básicamente dos: el llamado Full Frame, con un tamaño de fotograma de $24^{\times} 3^{6} \mathrm{~mm}$, equivalente al de la película de formato pequeño o paso universal, y el $A P S$ - $C$, con un tamaño aproximado de $22{ }^{\times}{ } 5 \mathrm{~mm}$, que varía en función de la cámara. Ambos tienen la misma proporción $3^{\times}{ }_{2}{ }^{8}$

Los fabricantes de cámaras ofrecen una amplia gama de productos, desde las réflex básicas hasta los modelos más profesionales. Al igual que con cualquier máquina o herramienta, su elección se ha de realizar en función de varios factores, desde el presupuesto con el que se cuenta al empleo que se le dé. Una cámara de gama alta obviamente tiene una mayor resistencia al uso frecuente gracias a la calidad de sus materiales y acabados, pero a costa de un mayor peso, volumen y precio. Por otro lado, en el segmento de las SLR los modelos de la gama superior están orientados a la fotografía de reportaje de acción, por lo que ofrecen una gran fiabilidad en el sistema de enfoque y medición de la exposición, así como una ráfaga extremadamente rápida. Sin embargo, en la fotografía de documentos no necesitamos tales prestaciones, ya que se trata de sujetos estáticos bajo una situación de luminosidad controlada. Es preferible una cámara cuya configuración esté orientada a obtener la máxima calidad de imagen, que suelen situarse en una gama intermedia de precios.

Recientemente han aparecido en el mercado las denominadas "cámaras sin espejo" o "cámaras compactas de objetivos intercambiables" (también llamadas CSC o EVIL), que ofrecen algunas de las características asociadas a las SLR con un menor peso y tamaño, pero también con una inferior calidad de imagen, una gama de objetivos más reducida y un sistema de encuadre y enfoque menos preciso, por el momento.

\section{I.3 Lentes}

Para la fotografía de páginas de libro o manuscritos completos lo aconsejable es emplear una distancia focal equivalente a un objetivo estándar (un $35 \mathrm{~mm}$ para una cámara APS o un $50 \mathrm{~mm}$ para una FF) o un teleobjetivo corto (un 50, 55 6o mm para una cámara APS y un 7o, 80, 90 mm para una cámara FF). La razón es una mejor reproducción de la perspectiva visual, es decir, una representación de las distancias entre los diferentes planos de la escena con unas proporciones similares a las ofrecidas por nuestro sistema de visión. Por otro lado, el teleobjetivo también tiene la ventaja de proporcionar un ángulo de cobertura menor que facilita el proceso de iluminación sin que aparezcan reflejos en la superficie del papel, como se explicará en artículos posteriores. Se ha de considerar que la DF elegida estará condicionada inevitablemente por el tamaño del documento a fotografiar y la altura del soporte elegido. La fotografía de detalles del texto y el equipamiento adecuado para este fin se tratarán en un apartado específico de próximas entregas.

Si lo que se busca es la excelencia, se aconseja emplear objetivos de distancia focal fija. Tienen

8. La gran variedad de tamaños de sensor que incorporan las modernas cámaras digitales, particularmente en los formatos más pequeños, ha propiciado la necesidad de emplear una referencia estándar para facilitar la previsualización del ángulo de visión de cada distancia focal. Al inicio de la revolución digital se optó por utilizar el tamaño del fotograma de la película de formato pequeño, estableciendo una equivalencia entre la DF real del objetivo y la supuesta si la cámara tuviera ese tamaño de imagen. Para más información se puede consultar el tutorial de Sean McHugh en la web Cambridge in Colour (http://www.cambridgeincolour.com/tutorials/digital-camera-sensor-size.htm), donde se explica de manera muy clara el efecto de recorte y multiplicación de las distancias focales, así como de sus consecuencias en la calidad de la imagen. 
una mayor resolución de imagen y las aberraciones ópticas (aberración cromática, esférica o geométrica) están mejor corregidas. Ciertamente, algunos de estos defectos de la lente pueden ser subsanados posteriormente en la edición digital de la imagen, pero siempre es más conveniente disponer de una materia prima con la mayor calidad posible. Un zum (zoom) es más económico y resulta más cómodo de utilizar por su versatilidad. Evidentemente debido a la complejidad de su diseño óptico, se pierde calidad; pero un buen zum cubrirá perfectamente las necesidades habituales de los trabajos que requiera la documentación filológica.

$$
\text { 3.I.4 RAW }
$$

El formato RAW ('en crudo' o 'en bruto’) es el único que permite trabajar directamente con la información proporcionada por el sensor sin procesar, con todas las ventajas que esto supone:

- Información en bruto que permite editar los datos de la imagen para visualizar en función de su rango dinámico (luz visible).

- Capacidad para trabajar a 8, I6 o 32 bits, dependiendo del tipo de cámara.

- Posibilidad de manipular los canales por separado.

- Visualizar en blanco y negro para dar contraste a las diferentes longitudes de onda del espectro visible.

- Posibilidad de crear varias versiones con diferentes ajustes del mismo archivo sin pérdida de información.

- Progresivo perfeccionamiento de los programas que facilitan la edición del archivo.

Obviamente, también tiene sus inconvenientes:

- Ocupa más espacio en la tarjeta de memoria

- Se trata de un formato propiedad de cada marca, por lo que es diferente para cada una y más específicamente para cada modelo de cámara que aparece en el mercado.

- Al no ser un archivo estándar, no se puede visualizar en los exploradores de internet ni con el sistema operativo Windows.

- Es necesario un programa especializado para poder visionarlo y editarlo, que requiere ser actualizado a medida que se incorporan nuevas cámaras al mercado.

$$
\text { 3.I.5 Calidad de imagen }
$$

La calidad final de una fotografía digital depende básicamente de cuatro factores:

$$
\text { 3.I.5.I La resolución }
$$

Es decir, el número de píxeles que compone la imagen. Esta característica viene determinada por el propio sensor de la cámara y actualmente se mide en megapíxeles. A mayor cantidad, mayor número de muestras toma el sensor de la imagen óptica proyectada por la lente sobre su superficie, incrementando así la información que capta.

$$
\text { 3.I.5.2 La profundidad de color }
$$

Con esta locución se expresa el número de bits que se asigna a cada píxel, lo que determina la cantidad de tonos que puede reproducir. El estándar son 8 bits, que permite 256 niveles de gris. La estructura básica de una fotografía digital en color está compuesta por tres canales, cada uno de ellos con la información de un color primario en la teoría aditiva, es decir, rojo, verde y azul, tradicionalmente nombrados por sus iniciales en inglés RGB. Si cada canal tiene 8 bits, la suma de los tres es de 24 bits, cuyas combinaciones proporcionan más de i6,7 millones de colores, 
suficientes para imitar la visión humana. Sin embargo, hay que tener en cuenta que, cuando se edita una imagen digital, se pierde información durante el proceso. Por ello, siempre que sea necesaria la mayor cantidad de datos posible, se trabaja en i6 o $3^{2}$ bits por canal. ${ }^{9}$ Inevitablemente, esto implica que la fotografía duplica o cuadruplica su tamaño (el peso del archivo), provocando lógicos problemas en su almacenamiento y manipulación en el ordenador.

$$
\text { 3.I.5.3 El ruido }
$$

El denominado ruido digital es una interferencia electrónica provocada por el propio funcionamiento del sensor, que se traduce en un granulado de la imagen causada por píxeles que son más claros o más oscuros, o tienen distinto color del que deberían. El ruido es más visible en las sombras de la imagen y aumenta al incrementar el valor de ISO y en las exposiciones prolongadas, a causa del calentamiento del circuito. Está directamente relacionado con el tamaño de los fotositos que, a su vez, depende del tamaño del propio sensor digital. Cuanto más pequeños son aquellos, mayor ruido se produce. En consecuencia, cuanto menor sea el mencionado sensor y mayor sea su número de píxeles, mayor ruido tendrá la fotografía. ${ }^{\text {IO }}$

\section{I.5.4 El rango dinámico}

Esta expresión (abreviada RD) designa el contraste que es capaz de reproducir una cámara digital. Es decir, la diferencia entre las zonas más claras y más oscuras de la imagen que queremos que aparezcan con detalle en nuestra fotografía. Cuanto más alto es el rango dinámico, mayor cantidad de información obtendremos, tanto en las luces como en las sombras. ${ }^{\text {II }}$

Teniendo en cuenta estos factores, la combinación ideal para obtener la máxima calidad sería trabajar con formato RAW y el ISO más bajo de nuestra cámara, entre Ioo y 200 dependiendo del modelo y marca. En consecuencia, lo más adecuado es disponer de una cámara que nos proporcione una alta resolución con una profundidad de color de $\mathrm{i} 6$ bits, el menor ruido posible con un rango dinámico amplio. No obstante hay que tener en cuenta que estas prestaciones ideales dependen del uso que vayamos a hacer de la imagen.

En el trabajo de documentación filológica a menudo es imprescindible tener una buena reproducción de los detalles para poder examinar con precisión el texto estudiado. Por ello, es

9. Como señala Hugo Rodríguez, es conveniente no pasar por alto que "la mayoría de archivos que un fotógrafo digital maneja están basados en estándares que pueden tener dos profundidades de color: 8 y i 6 bits/canal. (...) Por otra parte, muchas cámaras digitales generan archivos con una profundidad de color de I2 y en algunos casos I 4 y hasta I6 bits/c. Salvo estas últimas (muy pocas), todas las demás deben convertir al alza o a la baja la profundidad de color para poder ser transformadas en un archivo TIFF o JPEG. Si es a la baja será 8 y si es al alza será I6 (sólo válido en tif)” (Rodríguez 2OII, 8I).

IO. El control del ruido es una asunto complejo, por la variedad de factores que interviene en él, algunos de los cuales escapan al control del fotógrafo y están directamente relacionados con el tipo de sensor que lleve la cámara. Como señala Chris Weston, "El factor más importante en relación al ruido digital es la relación señal/ruido (SNR). La SNR hace referencia a la cantidad de ruido presente en un píxel en relación con la cantidad de señal. Un píxel puede tener mucho ruido, pero mientras tenga un contenido de señal significativamente más alto, los errores sumaran un pequeño porcentaje del contenido total y se perderán en el detalle” (Weston 20o8, 22).

II. Es conveniente aclarar que, tal y como destacan Efraín García y Rubén Osuna, el RD “depende, fundamentalmente, del tamaño real de las celdillas en que se alojan las fotocélulas y de la capacidad de diferenciar matices del conversor analógico-digital. Este intervalo o amplitud tonal se mide, en términos fotográficos, en 'pasos' (stops), en una escala logarítmica en la que cada ‘paso’ implica doblar la cantidad de luz del paso anterior” (García-Osuna 2OII, 5I). Así pues, el rango dinámico de una escena estándar varia entre 9 y I puntos. La visión humana tiene un RD que puede abarcar hasta 24 pasos de escala tonal en función de las variaciones de diámetro de la pupila, y con una abertura constante entre IO y I 4 pasos. En las cámaras digitales este valor depende de la calidad y tipo de sensor que incorporen, y oscila entre 5 y 9 puntos en función de la gama, llegado hasta los i2 en los respaldos de formato medio de calidad más elevada. 
lógico pensar que se requiere una gran resolución en la imagen. Sin embargo, todo depende de cómo se va a visualizar. Básicamente hay dos opciones: en pantalla o impresa. Los requerimientos de cada una son diferentes; la pantalla de un ordenador tiene una resolución estándar de 72 píxeles por pulgada; en cambio, la imagen impresa varía su grado de resolución ideal en función del tamaño y de la copia y del sistema de impresión. En artículos posteriores estudiaremos este tema con mayor profundidad.

\subsection{Soportes}

Dado que estamos fotografiando objetos estáticos normalmente en interiores y, por tanto, con un bajo nivel de intensidad luminosa, resulta imprescindible un soporte que sujete la cámara de manera estable, al mismo tiempo que nos permita alinear correctamente el plano del sensor con el documento retratado.

Efectivamente, para que no se produzca una distorsión en la perspectiva del texto, es necesario que la cámara este perfectamente paralela a la hoja, y esto sólo es posible si nivelamos ambos elementos. Realizar esta operación a pulso resulta francamente difícil y, aunque en la postproducción de la imagen podemos corregirla, como se explicará en próximas entregas, para un resultado correcto es imprescindible un sistema de sujeción adecuado. El mercado actual nos ofrece varias opciones: la base de reproducciones, la columna de mesa y el trípode.

La base o mesa de reproducciones es indudablemente el accesorio ideal para la labor de fotógrafo de objetos planos y tamaño pequeño, ya sean imágenes o textos, dado que ha sido específicamente diseñada para este fin. Se trata básicamente de un tablero, que sirve de apoyo para el documento objeto de estudio, dotado de una columna mecanizada y graduada que dispone de un soporte articulado para la cámara que se puede regular en altura.
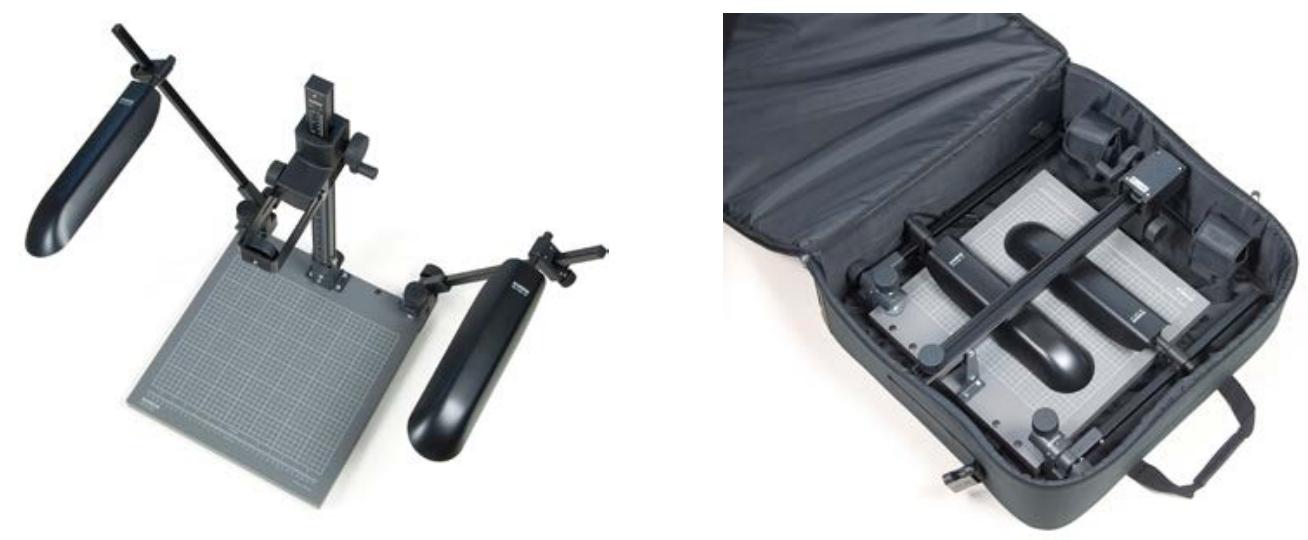

I. Mesa de reproducciones $\mathrm{R}_{2} \mathrm{~N}$ CP de Kaiser. (C) Kaiser

(http://www.kaiser-fototechnik.de/en/produkte/2 I produktanzeige.asp?nr=5304).

Garantiza un perfecto paralelaje, a la par que una gran estabilidad, pero tiene el inconveniente de que su diseño hace que sea un objeto voluminoso. Se fabrica en diferentes tamaños, pero incluso la más pequeña es incómoda de transportar. Esta es su principal desventaja, ya que, según se comentó al inicio, las fuentes primarias generalmente son documentos que no se pueden sacar de su lugar de conservación y es necesario fotografiarlos in situ. No es raro que las bibliotecas 
importantes dispongan de una mesa de reproducción, pero estas no siempre están a disposición de los investigadores. Por otro lado, en otros archivos no se dispone de este útil accesorio. Para estas situaciones, y para quien prefiera emplear su propio equipo, existe un modelo con la columna plegable de la marca Kaiser, que simplifica su transporte al caber todo el dispositivo en una maleta de tamaño y peso razonables.

Para aquellos estudiosos que consideren la mesa de reproducciones demasiado voluminosa y cara, la denominada columna de mesa es una opción más ligera y económica (vid. http://www. manfrotto.us/table-attached-tripod-column-post). Este accesorio vendría a ser un eje vertical con engranajes que incorpora una pinza para sujetarla en cualquier mesa, de esta manera se reduce considerablemente el peso y volumen. En realidad no está diseñada para ese fin específico, pero con una rótula adecuada que permita inclinar la cámara noventa grados puede adaptarse a la reproducción de documentos escritos.

Otra alternativa más conocida es el trípode. Al igual que en el artefacto anterior, su función original no es exactamente la que estamos tratando; no obstante, algunos modelos profesionales convenientemente empleados pueden ajustarse a las necesidades del filólogo. Un buen trípode debe presentar dos partes diferenciadas que se compran por separado: las patas y la rótula. En las primeras hay que buscar un tamaño y peso equilibrado a nuestras necesidades de transporte. Por lo general, cualquier marca especializada ofrece una amplia variedad de medidas entre las que es recomendable la gama intermedia. Es necesario que tengan un cierto peso para otorgar estabilidad, pero no tanto como para que su carga sea incomoda. Por otro lado, también es aconsejable algún modelo que ofrezca la posibilidad de girar noventa grados la columna del eje central, como veremos más adelante.

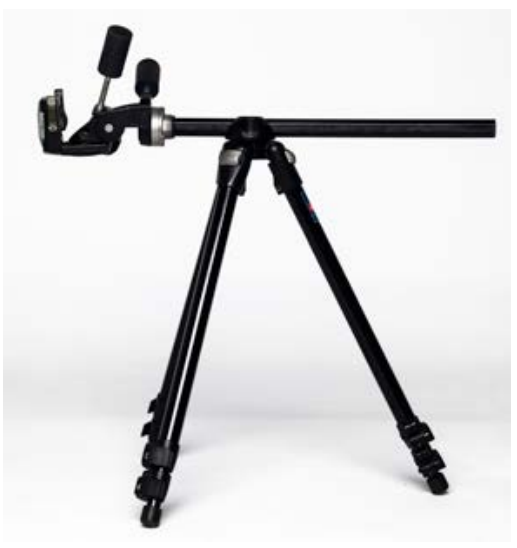

2. Trípode con columna horizontal. (C) Ricardo Guixà

En cuanto a la rótula, existen dos posibilidades: las rótulas de fricción, también denominadas ${ }_{3} \mathrm{D}$, y las rótulas de bola. Las primeras suelen incorporar niveles en el eje horizontal y vertical, y tienen la ventaja de permitir un control muy preciso sobre los tres ejes del desplazamiento en el espacio; sin embargo resultan más pesadas y difíciles de manejar que la otra opción. Las rótulas de bola permiten una uso ágil e intuitivo por la sencillez de su manipulación, a la par que son más ligeras y pequeñas, pero a costa de perder algo de precisión en el posicionamiento de la cámara. La versión con diseño de joystick otorga una mayor facilidad en la manipulación de los movimientos. Todas ellas se fabrican en diferentes tamaños, en función del peso y volumen de la cámara con la que se vaya a utilizar. 

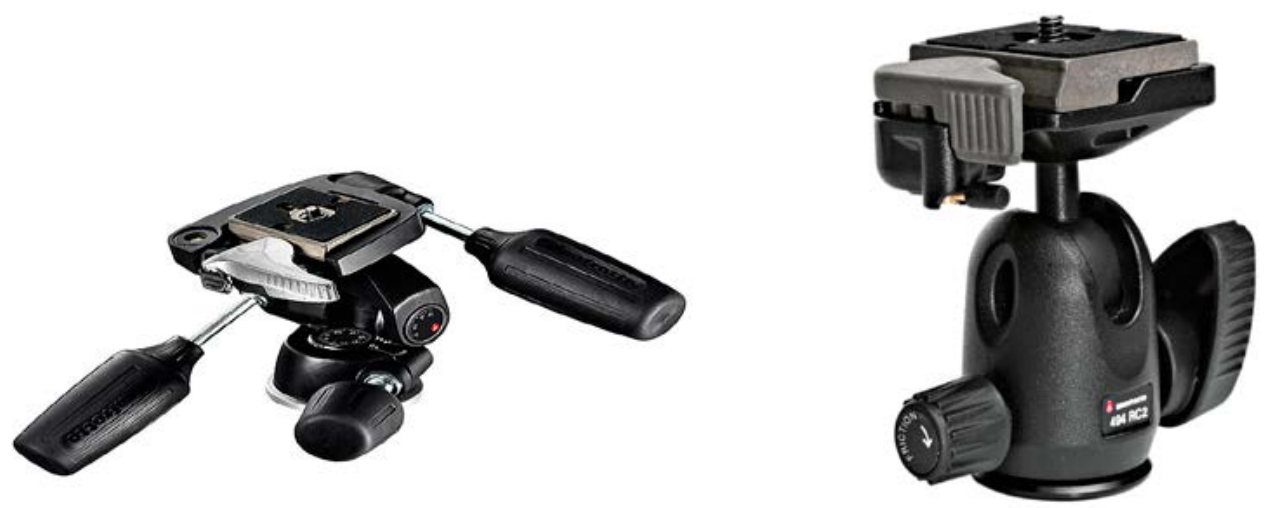

3. Rótula de fricción (derecha) y de bola (izquierda) de la marca Manfrotto. @ Manfrotto

Para fotografiar un documento escrito, la opción más sencilla consiste en situar el texto entre las patas e inclinar la cámara hacia él, procurando un perfecto paralelaje mediante un correcto nivelado. El principal inconveniente de este método es que las patas dejan un espacio reducido con poco margen de maniobra para encuadrar con la cámara sin que estas aparezcan en la toma, limitando el tamaño de los objetos a fotografiar. La alternativa más aconsejable es utilizar un trípode que tenga la opción de cruzar el eje horizontalmente para poder situar la cámara paralela al plano del soporte. De esta forma disponemos de un mayor espacio para ubicar los documentos a retratar, tal y como se explica más adelante.

Para una mejor sujeción del texto se comercializan diferentes complementos de gran utilidad. Cabe destacar las bases regladas con soportes magnéticos pensadas para inmovilizar láminas sueltas de distintas medidas (imagen) y las prensas de cristal, sumamente prácticas para la fotografía de libros, ya que facilita mantenerlos abiertos y con las hojas perfectamente planas, aunque pueden resultar algo agresivas para manuscritos sobre pergamino. Hay modelos que incluso son capaces de ajustar la presión automáticamente. Obviamente, no están diseñados para ser portátiles.
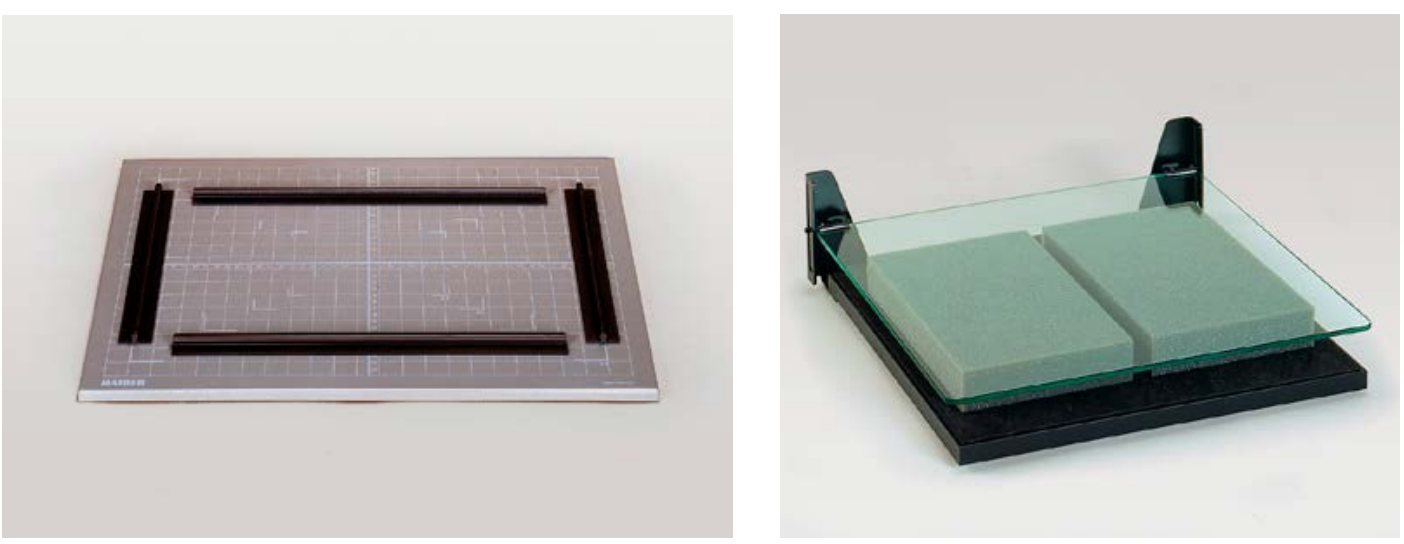

4. Soportes Kaiser. (C) Kaiser

http://www.kaiser-fototechnik.de/en/produkte/2_I_sortiment.asp?w=253 
Si empleamos una rótula de bola para este tipo de menester, un accesorio imprescindible son los niveles de cámara. Existen diferentes tipos, electrónicos o mecánicos, pero todos se sitúan en la zapata del flash y garantizan la correcta alineación entre el sensor y el texto una vez ajustados correctamente.

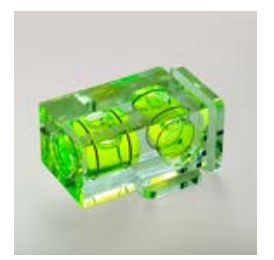

5. Nivel de burbuja en los ejes horizontal y vertical, diseñado para ser colocado en la zapata del flash.

(C) Ricardo Guixà

Mención aparte merece el dispositivo BookDrive, fabricado por la casa Atiz (http://pro.atiz.

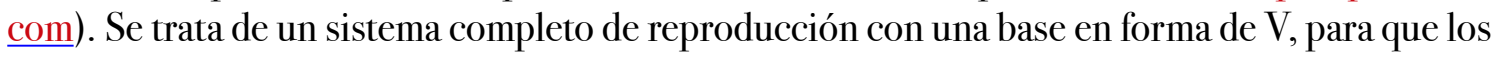
libros sufran el menor daño posible, que incorpora un soporte para dos cámaras, una para cada lado del documento, un sistema de iluminación led y un ordenador con software específico para procesar textos. Debido a su facilidad de manejo y tamaño compacto, gracias a un ingenioso diseño, es ideal para bibliotecas e instituciones; sin embargo, su peso y volumen hacen inviable su fácil transporte, por lo que no se tratará de él en este artículo.

\section{$3 \cdot 3$ Iluminación}

Para la reproducción de textos necesitaremos una fuente de iluminación de potencia y color adecuados. Básicamente existen dos opciones: incandescentes, como las bombillas o las lámparas halógenas, y no incandescentes, como los fluorescentes, bombillas de bajo consumo o los leds. Estas segundas tienen la ventaja de que son luces frías, por lo que apenas se calientan, y una mejor eficiencia energética.

Por otro lado, desde el punto de vista fotográfico siempre es preferible que sobre luz a que falte, ya que hay maneras de limitar su paso al interior de la cámara. Además, por lo general preferimos bajas sensibilidades, para evitar un incremento del nivel de ruido, tal y como se ha explicado. No obstante, al estar fotografiando objetos estáticos con la cámara firmemente sujeta, la potencia de la fuente de iluminación no resulta tan importante, ya que podemos emplear tiempos de obturación lentos sin pérdida de definición ni trepidación en la imagen.

Otro aspecto fundamental a tener en cuenta es el color de la luz. Se considera luz blanca aquella que está compuesta a partes iguales por los tres colores primarios de la teoría aditiva: rojo, verde y azul. En la luz natural, los rayos directos del sol son los únicos que cumplen esta característica, y entre las fuentes de iluminación artificial, el flash, algún tipo especial de fluorescentes y los leds, así como las lámparas metal halógenas (HMI). Habitualmente las mesas de reproducción emplean fluorescentes compactos con una TC de $5400 \mathrm{~K}$ o, más recientemente, leds luz día TC $5600 \mathrm{~K}$, mucho más eficientes energéticamente. ${ }^{\mathrm{I2}}$

I2. Conviene aclarar que “el concepto de 'temperatura de color' está basado en el calentamiento de un cuerpo. Partiendo de esta base, las fuentes de luz no incandescentes (...) que producen luz por otros medios no pueden definirse según este método" (Langford 1998, II5). Sin embargo, la tecnología actual permite que este tipo de luces de espectro 
En la actualidad, las cámaras digitales son capaces de corregir dominantes de color mediante el denominado Balance de Blancos (WB). Este control equilibra los tres canales RGB que componen la imagen para conseguir grises neutros. Las cámaras vienen configuradas de fábrica con un ajuste automático (AWB). Por lo general es bastante eficaz con una luz natural estándar, como la luz directa del sol. Sin embargo, dependiendo de la fuente de iluminación, no siempre resulta preciso, particularmente con los fluorescentes y luces incandescentes, por lo que no es el más adecuado para el uso concreto que se plantea en este artículo. Por otro lado, también existen modos preajustados a situaciones luminosas específicas como bombillas, sombras o flash. No obstante, no siempre se corresponden con la temperatura de color real emitida por la fuente de luz debido a la gran variedad de modelos que ofrecen los fabricantes, a la complejidad de la propia luz y a las limitaciones propias del sistema. ${ }^{13}$ Por ello, lo ideal es crear un balance de blancos personalizado, como veremos más adelante, o elegir la TC de la luz en grados Kelvin, si la cámara dispone de esta opción y conocemos el dato exacto.
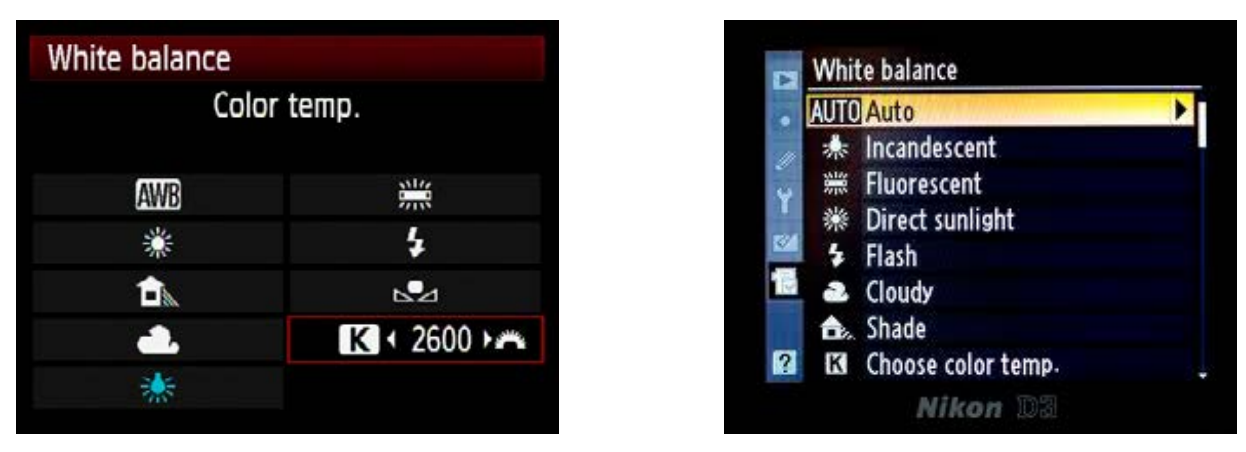

6. Menú del Balance de Blancos de una cámara Nikon, a la derecha, y Canon, a la izquierda. (C) Ricardo Guixà

En el proceso de trabajo con RAW es posible modificar el equilibrio de color al editar la imagen en el archivo sin procesar y, por tanto, sin la separación en las tres capas RGB. De esta manera, si se ha cometido algún error, es posible subsanarlo fácilmente. Pero un WB correcto sigue siendo imprescindible cuando se busca una exposición precisa, porque un equilibrio de color alterado modifica el histograma mostrado por la cámara, induciéndonos a error. Lo que nunca se debe hacer es iluminar con luces de distinto color, ya que la cámara sólo puede realizar un único Balance de Blancos para toda la escena y una de las dos fuentes dará a la fotografía una dominante que será muy difícil de corregir.

discontinuo imiten con bastante eficacia el espectro continuo de los radiadores térmicos, por lo que a efectos prácticos la temperatura de color que se le atribuye es equivalente a la que le correspondería si fuera una luz incandescente.

I3. En función de lo comentado en la nota anterior, Bob Atkins señala: "Most white balance settings assume that the incident light follows some sort of smooth black body type curve. For hot radiators (tungsten filaments, the sun) this is close to being true. However there are light sources (lasers, LEDs, fluorescent tubes, Neon lights) that are not black body radiators. They have what is called a line spectrum or discontinuous spectrum. While lamp makers try their hardest to make light sources like LEDs or Fluorescent tubes emulate continuous black body sources, they can't do it perfectly" (Atkins 2OIO). En consecuencia, los WB automáticos y los modos preajustados encuentran dificultades pera realizar el balance de color con precisión. 


\section{$3 \cdot 4$ Fotómetro y carta de gris medio}

Las cámaras réflex llevan un fotómetro incorporado en su interior que permite calcular la exposición, es decir, la combinación de diafragma y tiempo adecuada en función del ISO ajustado y la luz existente, para que la imagen obtenida se corresponda con nuestra percepción visual de esa misma escena. ${ }^{\mathrm{I}}$ La medición realizada por la cámara es siempre de la luz que refleja la superficie fotografiada, ya sea en su conjunto o de forma selectiva, dependiendo del modo elegido en el menú del fotómetro.
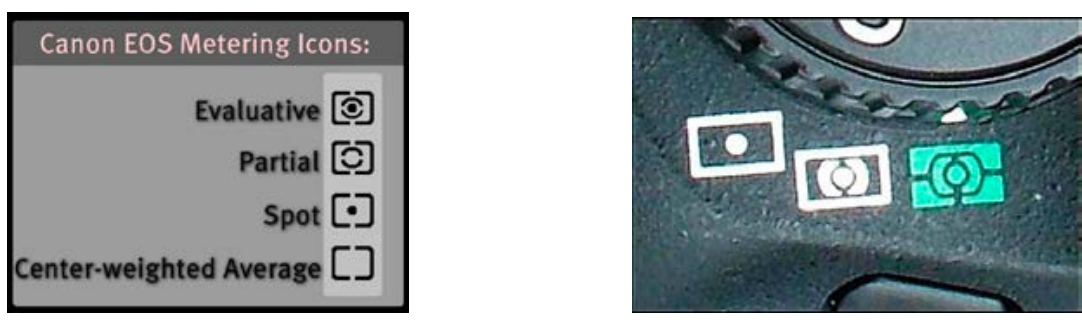

7. Menú de de sistemas de medición de Canon, a la izquierda, y Nikon, a la derecha. @ Ricardo Guixà

Para obtener una exposición correcta, el programa deja pasar el ı8\% de toda la luz que llega a la célula del fotómetro, cantidad que se corresponde con el denominado gris medio. ${ }^{5}$ Este procedimiento está concebido para una escena estándar en la que haya luces y sombras, claros y oscuros, como es usual en la mayor parte de las situaciones que fotografiamos. A partir de estos datos, la cámara establece un promedio cuyo resultado suele ajustarse bastante a la visión humana. Sin embargo, hay dos situaciones especiales en las que el fotómetro se equivoca. La primera es cuando domina el blanco o lo claro en la escena; y la segunda, cuando domina el negro o lo oscuro. La fotografía de textos suele corresponderse con la primera excepción.

Como se ha visto más arriba, por lo general los manuscritos o los textos impresos tienen un soporte de papel o pergamino predominantemente claros. Este hecho implica que la medición directa con el fotómetro de la cámara nos dará una imagen subexpuesta. Para enmendar este error, podemos rectificar el cálculo incrementando la entrada de luz con un máximo de dos puntos. El inconveniente es que no resulta fácil determinar a simple vista cuál es la corrección adecuada para cada situación concreta.

A nivel profesional, se emplean tres métodos que garantizan un resultado óptimo: derecheo del histograma, medición en carta gris y medición de luz incidente. La primera y la segunda se realizan directamente con el fotómetro que incorpora la cámara, pero la tercera necesita un fotómetro independiente. Este accesorio puede ser digital o analógico, para medición de luz continua oflash;

I4. A este tipo de medición se lo denomina TTL y tiene la ventaja de que calcula la exposición teniendo en cuenta la superficie exacta de la escena a fotografiar, pero presenta el inconveniente de que es necesario interpretar la manera en que el fotómetro realiza la medición.

I5. Este sistema de medición fue diseñado teniendo en cuenta el comportamiento de la película y en base a su respuesta logarítmica a la luz. El sensor de una cámara digital es un dispositivo lineal, por lo que es necesario un nuevo estándar en el cálculo de la exposición, que se ha traducido en una variación en el porcentaje de luz sobre el que se calcula el gris medio. A pesar de que es difícil obtener datos oficiales de los fabricantes de cámaras, Chris Weston constata que "los fotómetros de las cámaras DSLR están calibrados con una desviación hacia los tonos más claros (alrededor de 0,3 a o,5 puntos)" (Weston 2008, 57). 
y simplifica el proceso de medición en circunstancias complicadas. Cuando se trabaja con una SLR no es imprescindible, si no se emplean flashes de estudio como fuente de iluminación. En el mercado podemos encontrar diferentes marcas, todas las cuales garantizan un buen resultado, pero es un aparato caro.

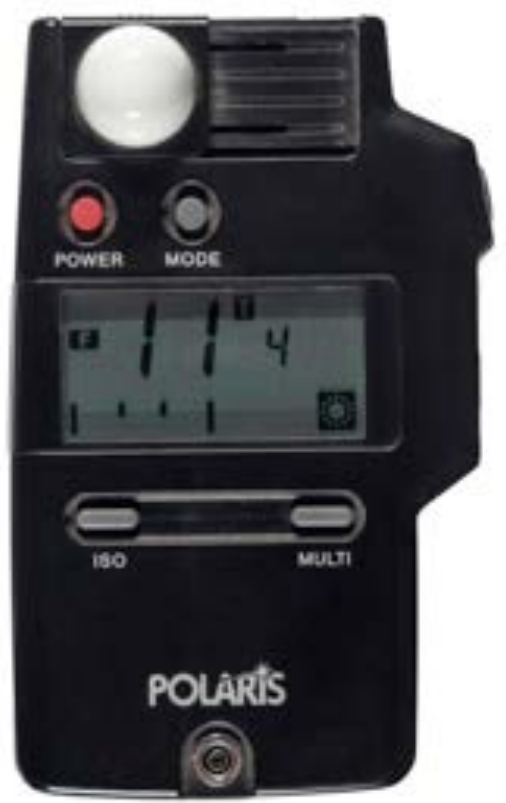

8. Fotómetro independiente digital. (C) Ricardo Guixà

Otro complemento realmente práctico en la fotometría es la carta de grises. Como su nombre indica, se trata de un cartón o una tela de color gris medio que refleja exactamente el ro \% de la luz, es decir, la que el fotómetro considera correcta. Se emplea para hacer mediciones sobre su superficie en situaciones en las que necesitamos asegurarnos una exposición exacta de motivos complicados, como el que nos ocupa. También se utiliza como referencia en los balances de blancos personalizados. Con cualquiera de los tres métodos, y particularmente con el primero, es aconsejable visualizar el histograma en su tres canales RGB para evitar cualquier pérdida de información, tal y como se ha comentado. ${ }^{16}$ En la mayoría de los documentos manuscritos o impresos, el canal rojo suele sobreexponerse antes que los otros dos, debido a la composición espectral de sus soportes más habituales, papel y pergamino, como se verá más adelante. En una cámara Canon, se activa con el botón de "INFO". En una cámara Nikon, es necesario ir al menú de "Reproducción" dentro de las opciones de visualización de reproducción, y seleccionar "Histograma RGB".

I6. El problema más habitual es la denominada sobreexposición parcial que provoca la pérdida de datos en las luces de alguno de los canales RGB, por lo que las zonas de la imagen afectadas aparecerían quemadas. "De cara a obtener una captura con la máxima cantidad de información posible, hay que evitar a toda costa que haya sobreexposición en cualquiera de los tres canales" (Rodríguez 2OII, I69). 

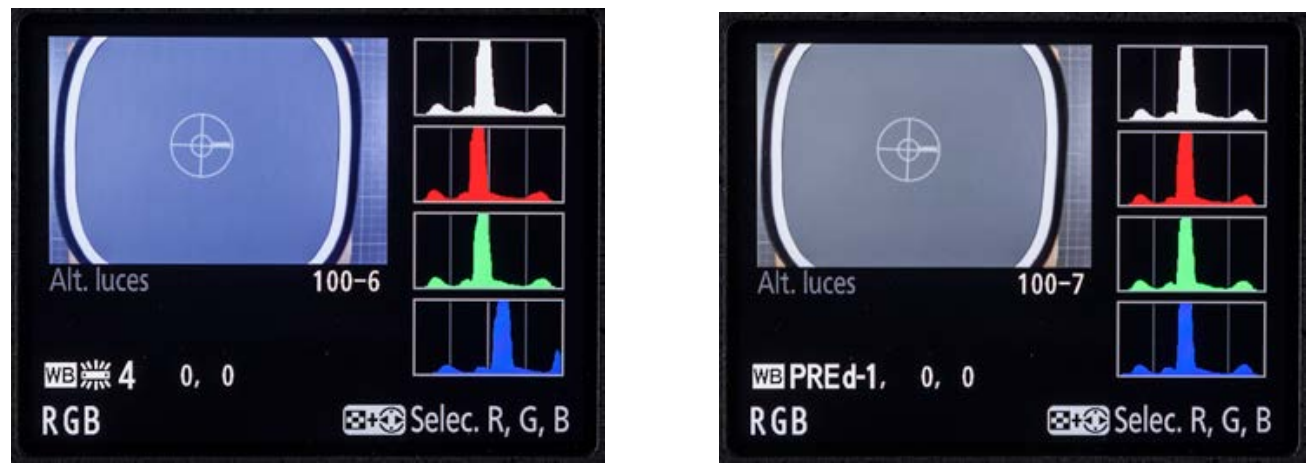

9. En la imagen de la izquierda el WB ajustado en fluorescente (luz empleada para su iluminación) da una dominante azul que se aprecia claramente por el desplazamiento del histograma. En la imagen de la derecha, con un balance personalizado en la carta gris, los tres canales son iguales. Cámara Nikon $\mathrm{D}_{7}$ IOo. (C) Ricardo Guixà

En la misma línea de complementos se encuentra la denominada carta de color, que incluye una serie de parches con los colores primarios, secundarios y espectrales, una escala de grises y una carta gris medio, imprescindible para una exacta reproducción del color en todas las fases del proceso.

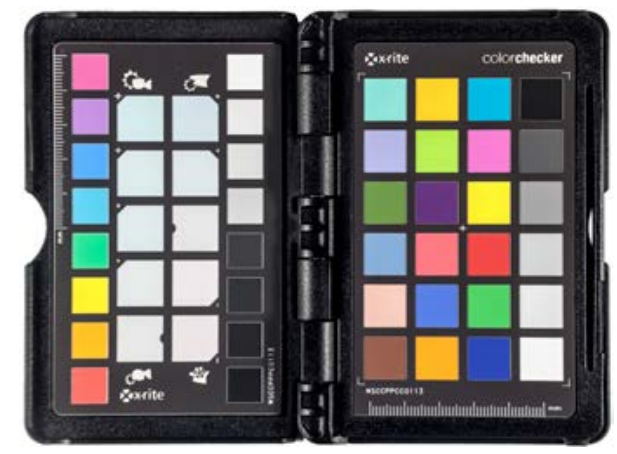

Io. Carta de color ColorChecker Passport de X-rite. (C) Ricardo Guixà http://xritephoto.com/ph product overview.aspx?ID=I257

\section{Captura de la imagen \\ 4.I Ajustes de la cámara}

En primer lugar hay que regular todos los parámetros de la cámara. En este artículo se han empleado una Canon EOS 5 D Mark II y una Nikon D 7 Ioo para ilustrar el proceso; pero cada marca, e incluso cada modelo, tiene su propio sistema de menús. Normalmente, los iconos y nombres empleados son parecidos, pero no siempre iguales y, en ocasiones, completamente diferentes. Por esta razón, se recomienda consultar el manual de instrucciones, en caso de duda, particularmente a los fotógrafos menos expertos. La elección dependerá de varios factores: algunos son variables según las preferencias y conocimientos del operador; otros son inexcusables, si se busca la máxima 
calidad final. ${ }^{17}$ Este es un buen punto de partida:

ISO: IOO o 200, el más bajo posible, para evitar el ruido digital.

WB: Seleccionar el balance de blancos personalizado o elegir la TC en grados Kelvin, si la cámara lo permite y se conoce el dato.

Calidad de imagen: RAW. Cuando se tiene suficiente espacio en la tarjeta de memoria, también se puede elegir RAW+JPG y así se dispone de dos versiones de la misma imagen en distinto formato, una sin procesar y otra procesada.

Estilo de imagen (Picture control en Nikon): Fiel o neutro. De esta manera nos aseguramos que el visionado de revisión en la propia cámara del histograma en RGB no esté modificado por los parámetros de saturación, contraste o enfoque ${ }^{\mathrm{r}}$.

Modo de disparo: En una cámara Canon, único; S en Nikon. Opcionalmente se puede hacer la fotografía con el disparador a distancia para asegurarse que no se produzca ningún tipo de trepidación. En tal caso es necesario seleccionar en el mismo menú la opción adecuada para cada cámara.

Modo de exposición: Manual (M).

Número $f$ : Se ha de cerrar dos puntos por encima de la máxima apertura. Por ejemplo, si nuestro objetivo tiene una luminosidad de 5,6 , se ha de ajustar en la cámara Ir. De esta manera se optimiza la calidad que es capaz de proporcionar la óptica, al evitar los defectos y aberraciones de los márgenes de la lente, y se gana en profundidad de campo. En ópticas muy luminosas o cuando el documente esté ondulado, se puede cerrar tres o cuatro puntos para aumentar la PC. ${ }^{19}$

Tiempo de obturación: Vendrá determinado por la lectura del fotómetro.

Modo de medición: Matricial o puntual, también denominado spot, en función del procedimiento elegido para el cálculo de la exposición.

Distancia Focal (DF): Para una cámara APS-C, entre 35 y 70 mm. Para una cámara FF, entre 50 y IOo mm, en función del encuadre.

Enfoque: Manual.

Espacio de color: Adobe RGB. ${ }^{20}$

I7. La importancia de este aspecto es crucial en el tema que nos ocupa, como asevera Jean-Claude Chirollet: "Ils sont fondamentaux en ce qui concerne le degré de fidélité des reproductions numériques des images d'œuvres d'art. Pour qu'une image d'art possède une valeur documentaire fiable, il est indispensable que son apparence sur divers types de supports soit conforme aux intentions qui ont déterminé la numérisation initiale, censée traduire de manière 'objective' et fidèle à la vérité crhomatique de l'œuvre original" (Chirollet 2005, I30).

I8. Cuando se trabaja en formato RAW, la imagen está por definición sin procesar, por lo que, teóricamente, no le afecta el estilo de imagen elegido, ya que no se aplica a la imagen. Sin embargo, el visionado en la pantalla trasera de la cámara sí que se muestra conforme al estilo seleccionado, y la exposición de la fotografía se verá afectada por los parámetros ajustados en él, alterando el histograma que nos sirve de guía.

I9. Todas las aperturas del diafragma están afectadas por la difracción en mayor o menor medida. Cuanto más cerrado esté, mayor será la desviación de la luz, provocando una perdida de definición en la imagen. "La capacidad resolutiva de un objetivo (aerial image resolution) depende de las aberraciones y la difracción. Cuando cerramos el diafragma las aberraciones se ven mitigadas y el único factor limitante es la difracción. Cuando abrimos el diafragma la difracción pierde importancia pero las aberraciones cobran fuerza" (García-Osuna 2OII, 7). En consecuencia las aperturas intermedias nos permiten un equilibrio entre ambas.

20. Con el fin de poder asegurar una correcta gestión del color a lo largo de todo el flujo de trabajo en los procesos 
Modo LV: Opcionalmente se puede seleccionar el modo de visionado en directo, si se quiere ajustar la exposición mediante la visualización del histograma en vivo.

Estabilizador (también llamado VR, IS y MegaIOS ): Desactivado. ${ }^{21}$

\title{
4.2 Proceso de trabajo
}

\author{
4.2.I Ajustar los parámetros básicos
}

Seleccionar el ISO, el modo de disparo, la calidad de imagen, el espacio de color, el estilo de imagen, el sistema de enfoque, el modo de exposición y el $n^{\circ}$ f recomendados.
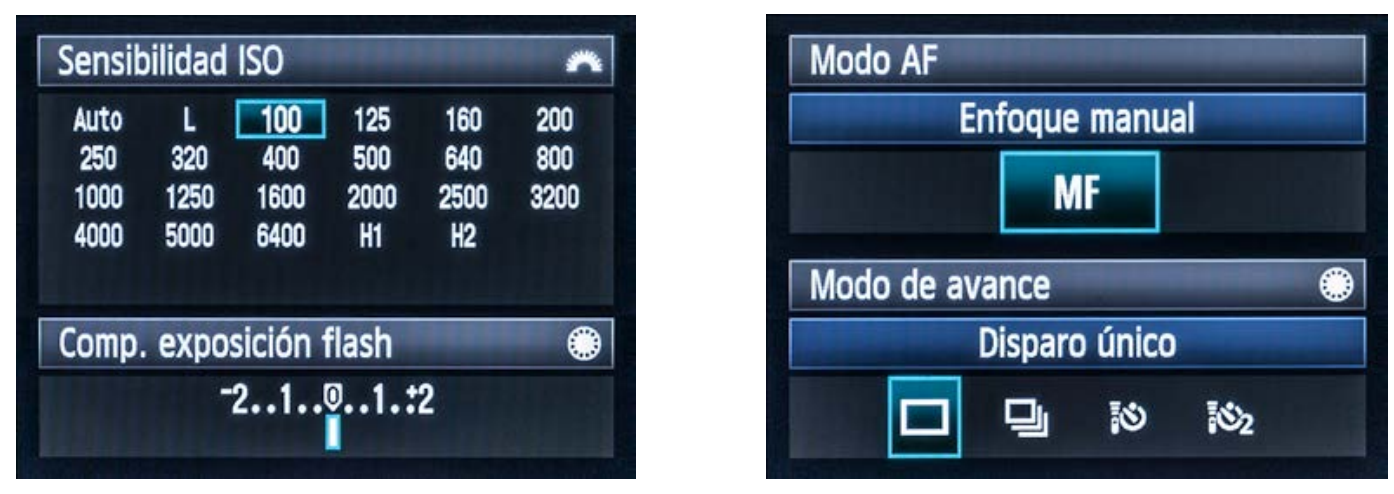

II. Sensibilidad, enfoque y modo de disparo en una cámara Canon EOS 5 D Mark II. C Ricardo Guixà

informáticos, el ICC (International Color Consortium) creó una normativa internacional que permite definir diferentes formatos de perfiles que describen los atributos de color de un dispositivo en particular. El espacio de color es una lista estándar de colores codificados. En la actualidad, las cámaras pueden elegir entre dos opciones: s-RGB y Adobe RGB. El primero es el estándar de Internet, pero el segundo dispone de una paleta de colores más amplia, por lo que es preferible cuando se busca la máxima calidad en la captura. A efectos prácticos, en el formato RAW se puede elegir este parámetro al editar la imagen, como se estudiará en posteriores artículos. Es conveniente recalcar que en la era de la fotografía digital, la gestión de color es una cuestión fundamental, particularmente en todo el proceso de documentación. Como señala Andrew Rodney, "It is important to understand that color is a human perception, a sensation inside our brains. All the colors displayed on a computer system are just numeric values, and unfortunately, numbers don't tell us what color looks like; rather, they provide a partial numeric recipe for color" (Rodney 2005, 8).

2I. Cuando la cámara permanece estable en su soporte, los elementos flotantes del sistema de estabilización pueden generar una trepidación artificial, además de consumir energía innecesariamente. El ingeniero de Canon Chuck Westfall da la siguiente explicación: "The IS mechanism operates by correcting shake. When there is no shake, or when the level of shake is below the threshold of the system's detection capability, use of the IS feature may actually *add* unwanted blur to the photograph, therefore you should shut it off in this situation. (...) Remember that the IS lens group is normally locked into place. When the IS function is active, the IS lens group is unlocked so it can be moved by the electromagnetic coil surrounding the elements. When there's not enough motion for the IS system to detect, the result can sometimes be a sort of electronic 'feedback loop', somewhat analogous to the ringing noise of an audio feedback loop we're all familiar with. As a result, the IS lens group might move while the lens is on a tripod, unless the IS function is switched off and the IS lens group is locked into place" (Westfall 2006). 

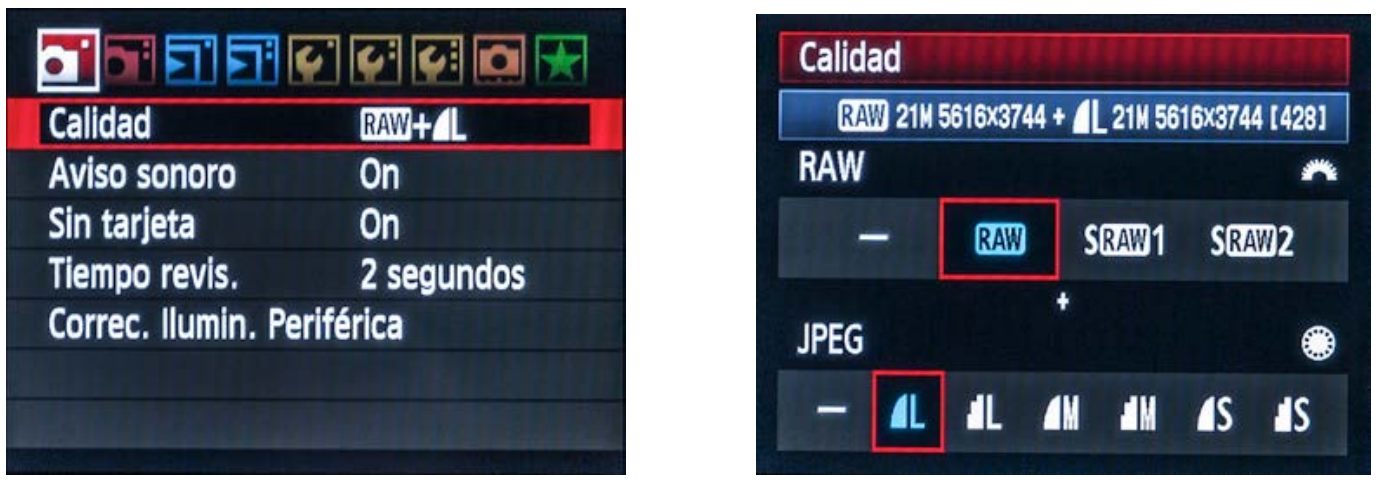

I2. Ajuste de calidad de imagen en una cámara Canon $\operatorname{EOS}_{5}$ D Mark II. @ Ricardo Guixà

\begin{tabular}{|c|c|}
\hline 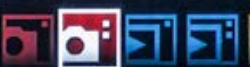 & 的回问 \\
\hline Comp. Exp./AEB & $-2 . .1 \ldots 0 . .1 . \div 2$ \\
\hline Bal. Blancos & $\Delta$ \\
\hline Bal. blancos pers & \\
\hline DESP/SEC BAL.B & $0,0 / \pm 0$ \\
\hline Espacio color & Adobe RGB \\
\hline Estilo imagen & Fiel \\
\hline Datos eliminaciór & alvo \\
\hline
\end{tabular}

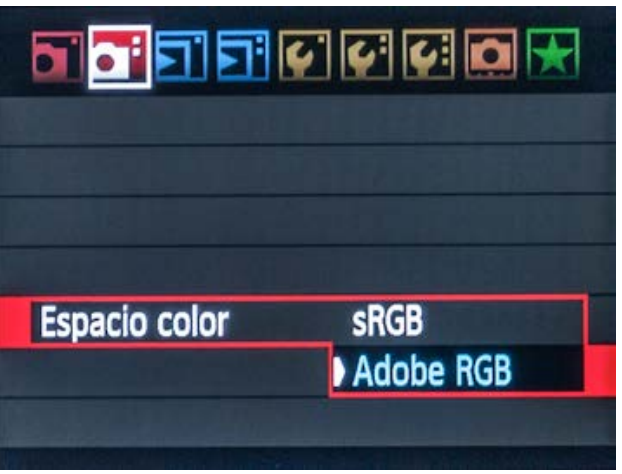

I3. Ajuste del espacio de color en una cámara Canon EOS 5D Mark II. C Ricardo Guixà

\begin{tabular}{|c|c|}
\hline Estilo imagen & (1). $0.8,0$ \\
\hline E*LPaisaje & $4,0,1,0$ \\
\hline E:3N Neutro & $0,0,0,0$ \\
\hline Ë:3FFiel & $0,0,0,0$ \\
\hline E.3MMonocromo & $3,0, N, N$ \\
\hline E:-1] Usuario 1 & Normal \\
\hline E:2 Usuario 2 & Normal \\
\hline INFO. Parám. detalle & SET 0 \\
\hline
\end{tabular}

\begin{tabular}{|c|c|}
\hline \multicolumn{2}{|c|}{ 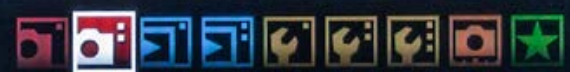 } \\
\hline Comp. Exp./AEB & $-2 . .1 . .0 . .1 . \div 2$ \\
\hline Bal, Blancos & $\Delta$ \\
\hline \multicolumn{2}{|c|}{ Bal. blancos personal } \\
\hline DESP/SEC BAL.B & $0,0 / \pm 0$ \\
\hline Espacio color & Adobe RGB \\
\hline Estilo imagen & Fiel \\
\hline Datos eliminació & polvo \\
\hline
\end{tabular}

I4. Estilo de imagen en una cámara Canon $\mathrm{EOS}_{5} \mathrm{D}$ Mark II. CC Ricardo Guixà. 


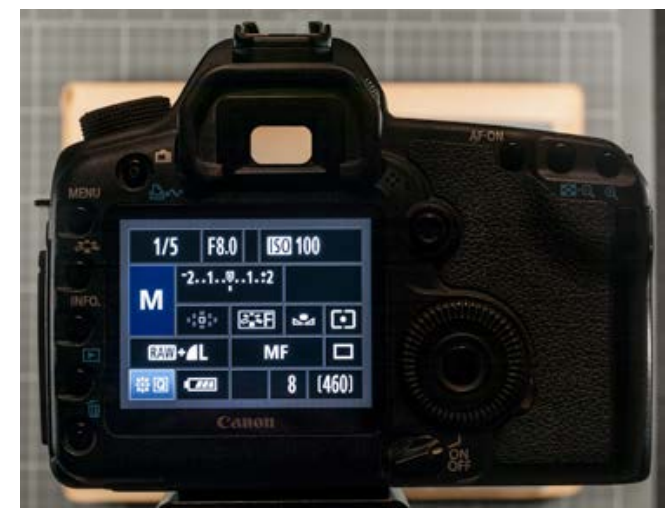

I5. Configuración recomendada en una cámara Canon EOS 5 D Mark II. El tiempo de obturación dependerá de la luz empleada. (C) Canon

En algunos modelos de cámara Nikon, la disposición de los controles varía sensiblemente con respecto a otras marcas. En los de gama media y alta, la principal característica es que hay dos pantallas. La superior se emplea para los ajustes de la cámara básicos y la trasera sobre todo para los menús y la visualización de las imágenes.

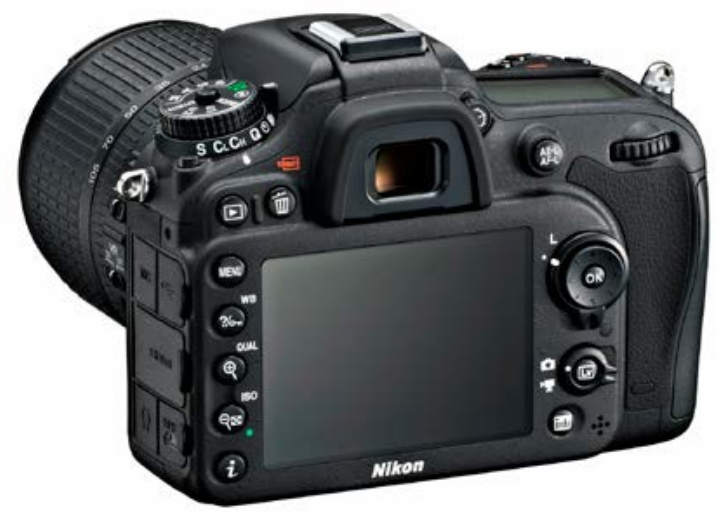

I6. Nikon D7ıoo. El ajuste de modo de disparo se encuentra en un dial situado habitualmente en la parte superior izquierda iniciado con la $\mathrm{S}$ de single. (C) Nikon
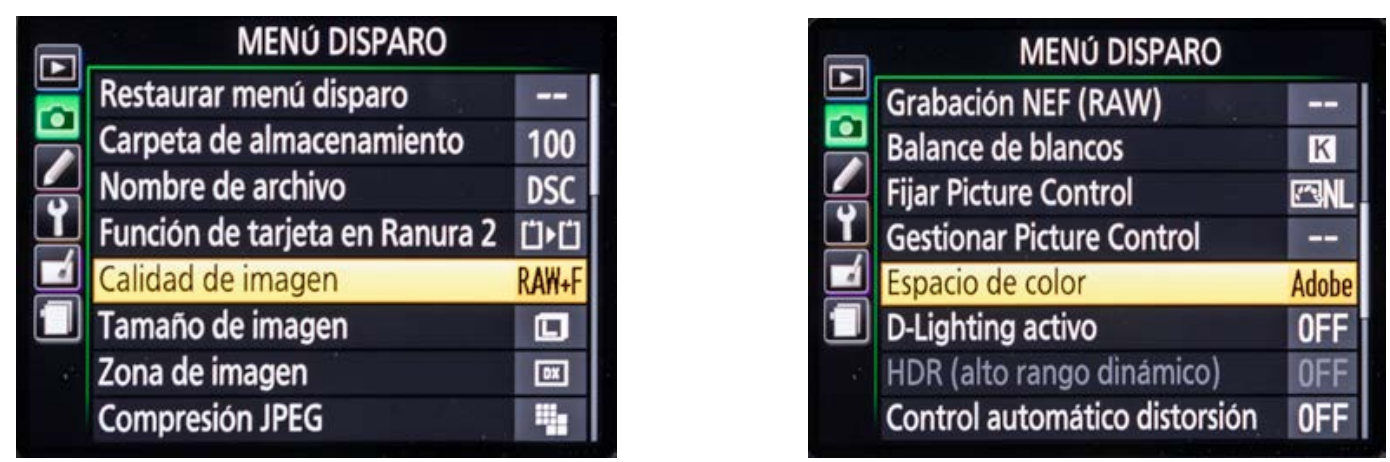

I7. Menú de calidad en una cámara Nikon D7ıoo. (C) Ricardo Guixà 

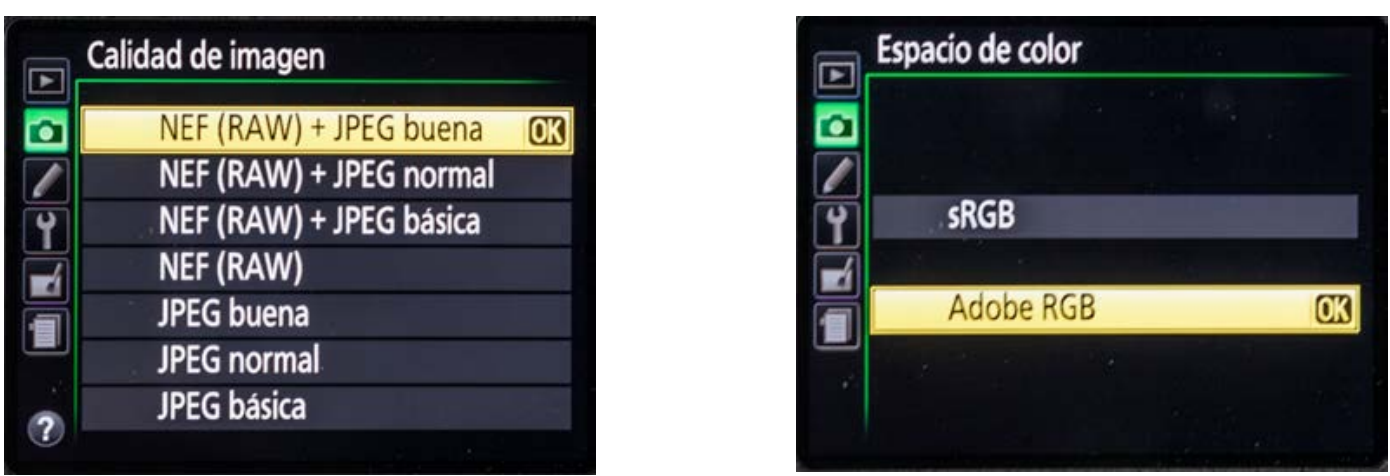

I8. Menú de Espacio de color en una cámara Nikon D7ıoo. (C) Ricardo Guixà

\begin{tabular}{|l|l|}
\hline \multicolumn{3}{|c|}{ MENÚ DISPARO } \\
\hline Grabación NEF (RAW) & -- \\
\hline Balance de blancos & $\mathrm{K}$ \\
\hline (2) & Control automático distorsión \\
\hline
\end{tabular}

\begin{tabular}{|c|c|}
\hline & Fijar Picture Control \\
\hline & FSD Estándar \\
\hline & $\mathrm{NL}^{\mathrm{N}}$ Neutro \\
\hline & 国VI Vivido \\
\hline 1 & FiCMonocromo \\
\hline Ed & EPT Retrato \\
\hline E & ESSPaisaje \\
\hline (2) & QQCuadricula CAjusta \\
\hline
\end{tabular}

I9. Ajuste de estilo de imagen en una cámara Nikon D7ıoo. C Ricardo Guixà

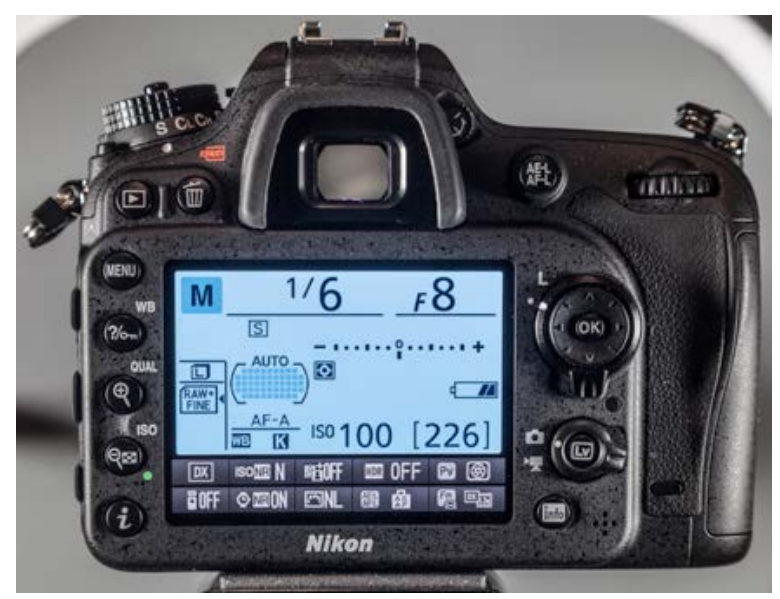

20. Configuración recomendada en una cámara Nikon D7Ioo. El tiempo de obturación dependerá de la luz empleada. (C) Ricardo Guixà

4.2.2 Situar la cámara en el soporte elegido

La base de reproducciones es la primera opción, siempre que sea factible. Si se emplea una columna de mesa o un trípode con el eje en horizontal, es imprescindible nivelar correctamente la cámara para garantizar el paralelaje con el texto. 


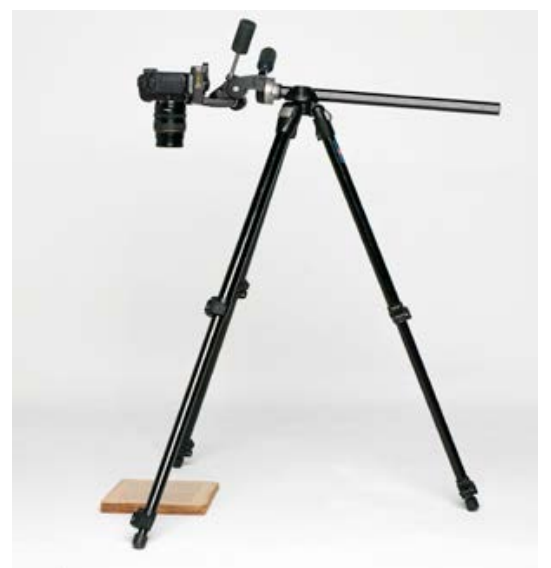

2I. Trípode Manfrotto con rótula de fricción. (C) Ricardo Guixà

Seguidamente hay que situar en la base el documento a fotografiar bien centrado, ajustar la altura y la DF, procurando dejar un cierto margen alrededor. Si se quiere un fondo neutro sobre el que destaque, se puede emplear una cartulina blanca, gris medio o terciopelo mate negro, u otra tela similar, en función del documento.

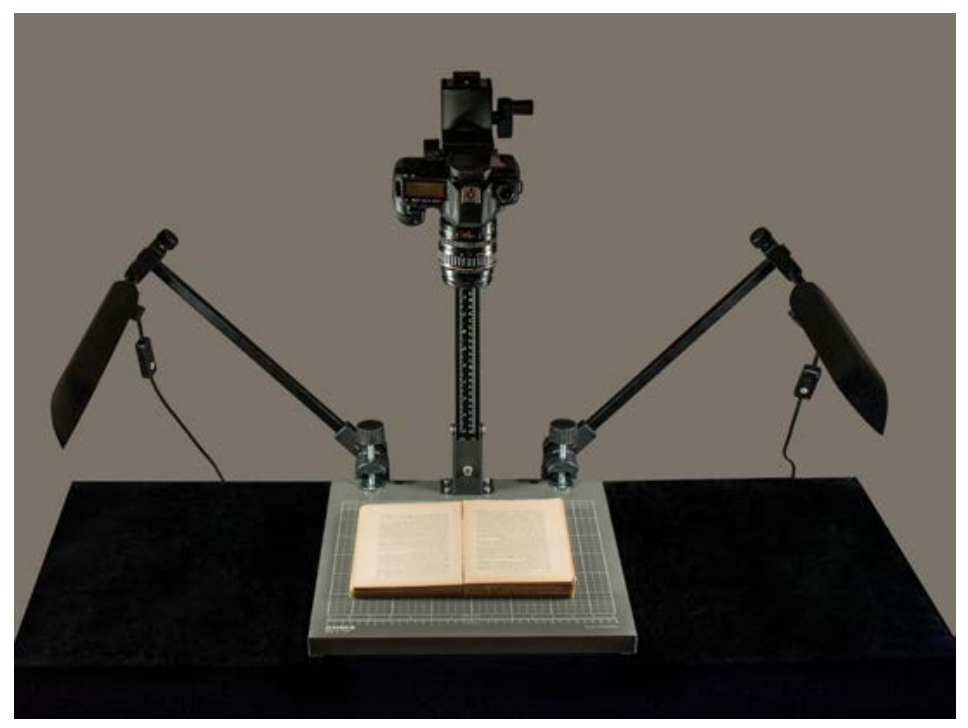

22. Mesa de reproducciones Kaiser con juego de iluminación. (C) Ricardo Guixà

\subsubsection{Iluminar la escena}

El esquema empleado dependerá del tipo de superficie a fotografiar. El caso más frecuente en la mayoría de las fuentes primarias es que aquella sea opaca, plana y mate. Para evitar que se produzcan reflejos que interfieran en la visibilidad del texto, se sitúan las fuentes de iluminación a los lados aproximadamente a $45^{\circ}$ del plano de la hoja, procurando una luz uniforme y sin sombras; para ello deben estar a la misma distancia y tener igual potencia y temperatura de color. El procedimiento para superficies brillantes se explicará en un artículo posterior. 
Las mesas de reproducciones tienen como accesorio básico un juego de iluminación particularmente diseñado para esta labor y que cumple los requisitos especificados. Consiste en dos brazos armados con la cabeza articulada para poder orientar las luces fácilmente. Si no se dispone de este complemento, se pueden utilizar dos pies de estudio plegables o cualquier otro accesorio que permita sujetar las lámparas en el ángulo adecuado.

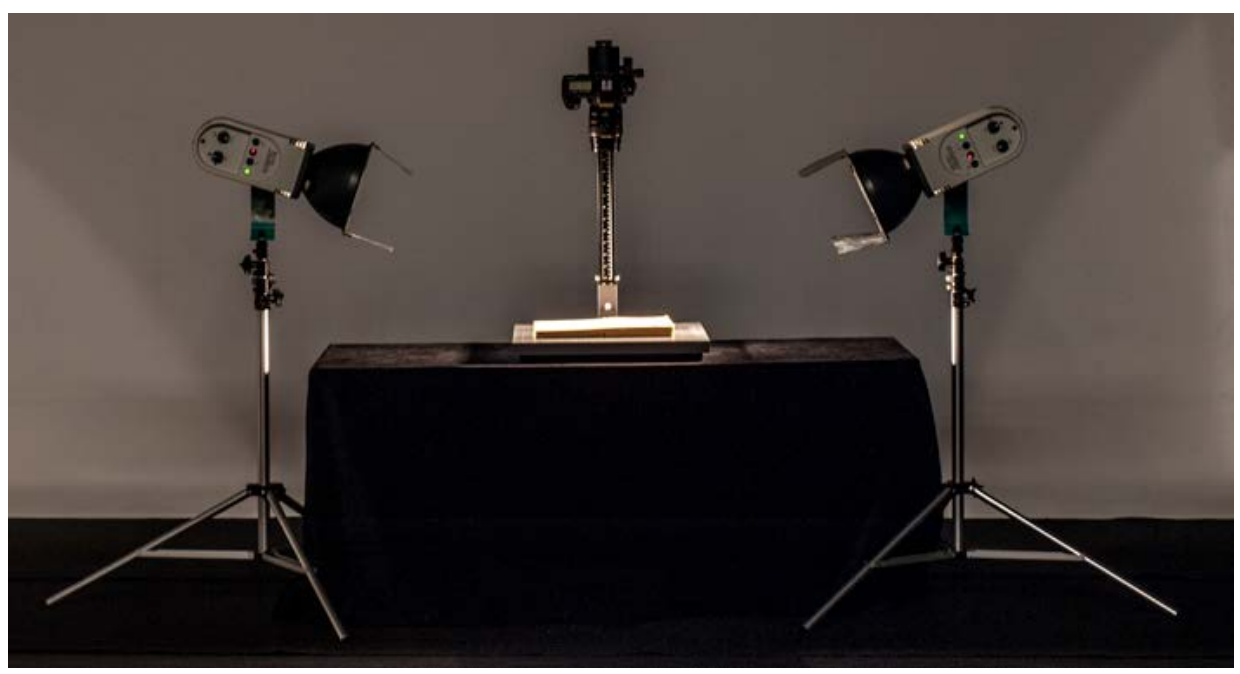

23. Pies de iluminación Manfrotto con flash Visatec. (C) Ricardo Guixà

\subsubsection{Enfocar el texto}

En superficies planas el enfoque resulta fácil y sin complicaciones, pero si el documento es un pergamino y está alabeado, presentando ondulaciones, es imprescindible enfocar a la distancia hiperfocal, es decir, aproximadamente a un punto intermedio entre el plano más cercano y más alejado de la cámara que queremos se vea nítido en la fotografía.. ${ }^{22}$ Esta operación hay que repetirla cada vez que se cambie de página o documento. En el modo Live View es posible activar el zum de la pantalla para un enfoque preciso.

22. Autores com Norma Koren o Harold M. Merklinger mantienen que la técnica de la distancia hiperfocal no se puede aplicar como una regla estricta, a causa de las limitaciones de nuestra agudeza visual y todos los factores que determinan la percepción de la imagen. "If the part of the scene at infinity is at all important in the image-it's often visually dominantyou'll be disappointed with the sharpness, which is only $40 \%$ that of a high quality lens in focus; about one third what the eye can distinguish. Merklinger recommends focusing at infinity-you lose very little forward depth of field. I feel safe setting infinity focus opposite the far DOF mark corresponding to 2 stops larger than the actual $f$-stop setting (half the number). For example, if you are using $f / 8$, it's safe to put the far $f / 4$ DOF mark opposite infinity. It's a judgment call. When you make it, think about what parts of the image will be dominant. There is no rule to blindly follow" (Koren 2 OI3). 


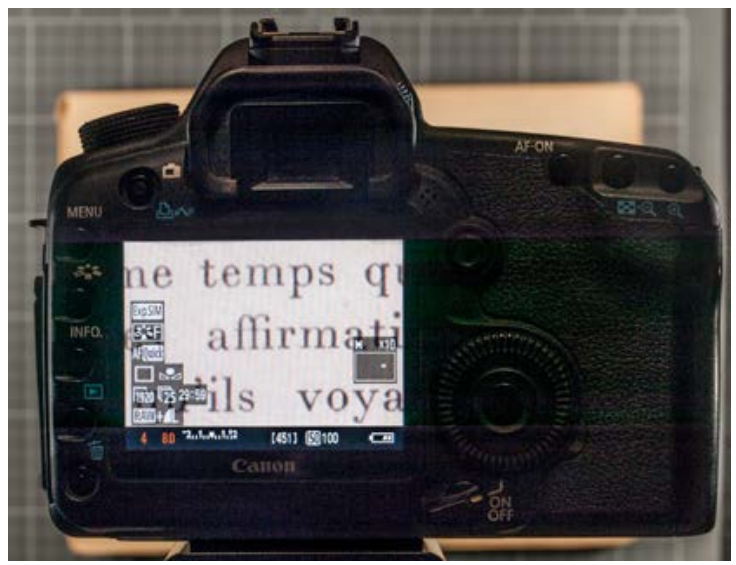

24. En una cámara Canon EOS 5 D Mark II el botón con el icono de una lupa situado en la parte superior derecha permite hacer un zum rápido específico para enfocar en modo LV. C Ricardo Guixà

\subsubsection{Ajustar el balance de blancos}

Hay dos opciones con garantías de precisión:

$$
\text { 4.2.5.I Balance de blancos personalizado }
$$

El procedimiento cambia según la cámara empleada, en función de la marca y el modelo, por lo que es necesario consultar el manual de instrucciones, si no se conoce la técnica. En cualquiera de los casos, necesitaremos una carta de blancos o grises. La carta de blancos tiene la ventaja de que es más clara y proporciona una mayor intensidad luminosa. No vale cualquier superficie blanca, lo ideal es que esté certificada, al igual que el gris medio. Es necesario que reciba la misma luz que el documento a fotografiar y que no quede sobreexpuesta. Para ello, el dial de exposición \pm debe estar a cero, aunque no hay problema si queda un poco subexpuesta.
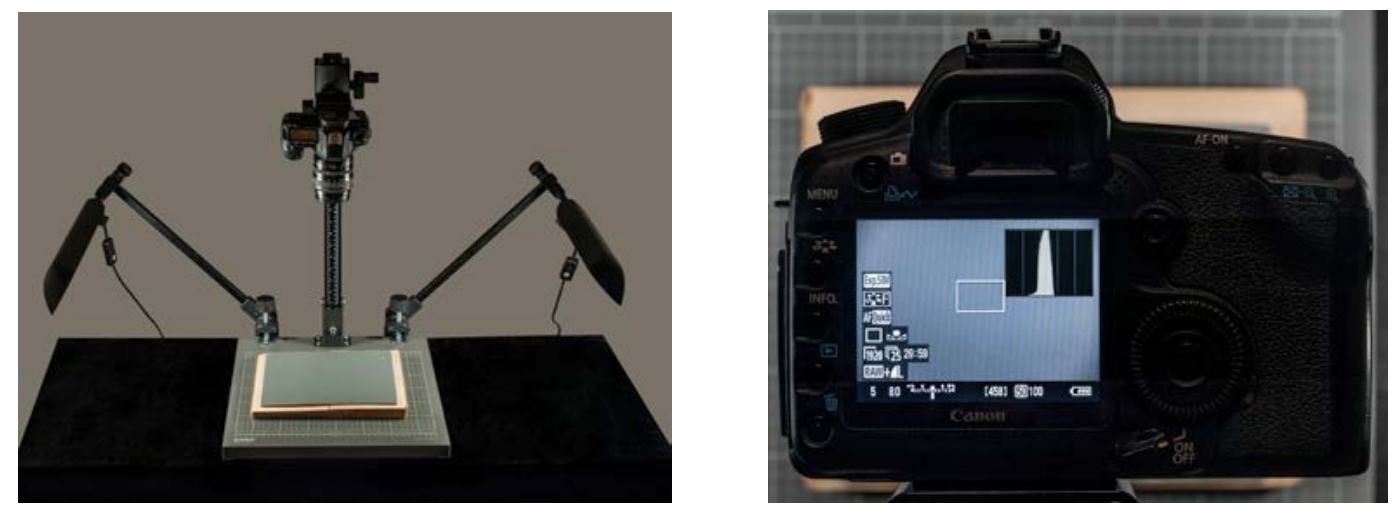

25. Carta de grises en la mesa de reproducciones y la imagen que se ve en la pantalla con el modo LV activado y la exposición correcta, según el fotómetro de la cámara. (C) Ricardo Guixà

No es necesario que ocupe todo el encuadre, aunque por precaución podemos optar por que lo llene completamente. El tanto por ciento exacto viene indicado en las instrucciones. Tampoco resulta imprescindible que esté nítida, por lo que no conviene tocar el anillo de enfoque ya ajustado. 
En una cámara Canon, primero hay que hacer la fotografía y una vez tomada ir al menú "Bal. blancos personal" y asignarle esa imagen.
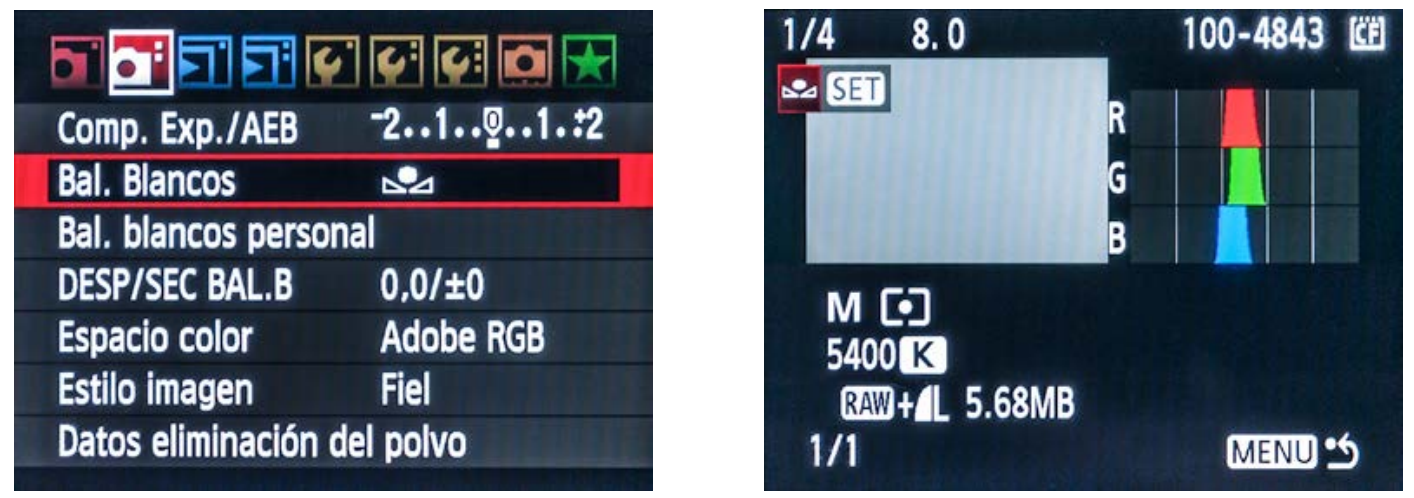

26. Por lo general, con cámaras Canon, una vez realizada la fotografía de la carta gris se selecciona el Balance de blancos personalizado y se elige esta imagen en la pantalla siguiente. (C) Ricardo Guixà
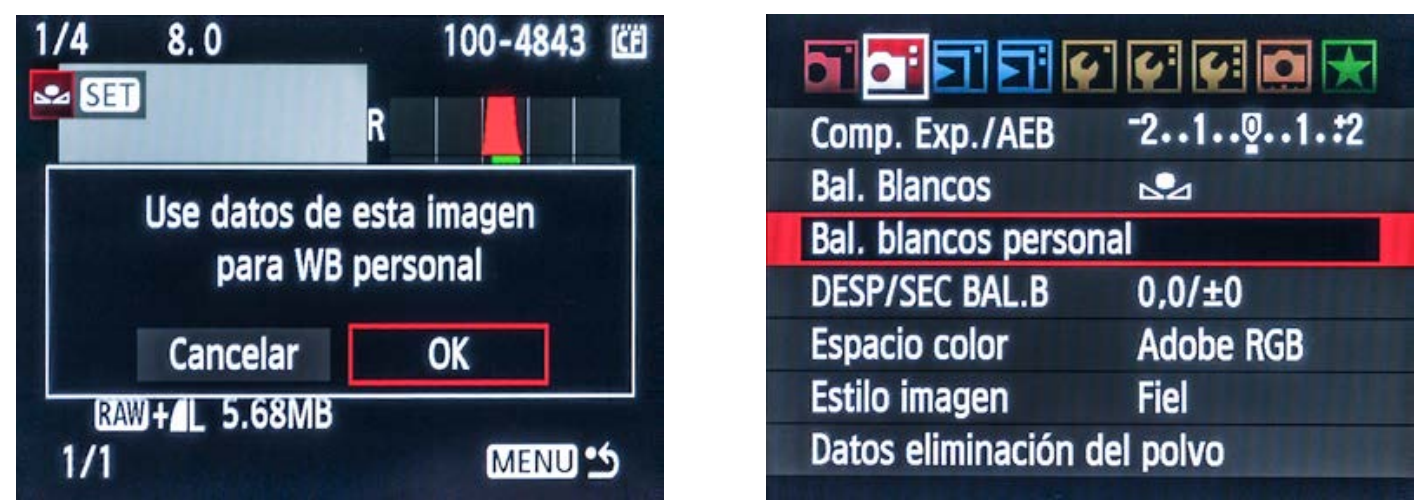
27. Seguidamente aparece otra pantalla, en la que debemos seleccionar OK. Por último, en el menú de WB
elegimos el modo personalizado. (C) Ricardo Guixà

En una cámara Nikon el método es más complicado y variable en función del modelo. El procedimiento consiste básicamente en seleccionar mediante el botón WB el modo "PRE” y mantenerlo presionado hasta que WB parpadee en la pantalla LCD superior. Luego se hace la fotografía y, si el resultado es correcto, aparece parpadeando en la misma pantalla la palabra "Good”, pero si ha fallado, se indicará "no Gd”, por lo que habrá de repetirse la operación. ${ }^{23}$

23. La marca Nikon no tiene un modo estándar para realizar un balance de blancos personalizado. El que se muestra en este texto es el más común en las cámaras actuales de gama media y alta, pero varía en modelos inferiores o más antiguos, e incluso algunos no incorporan esta función, por lo que resulta imprescindible consultar el manual de instrucciones en cada caso particular. 

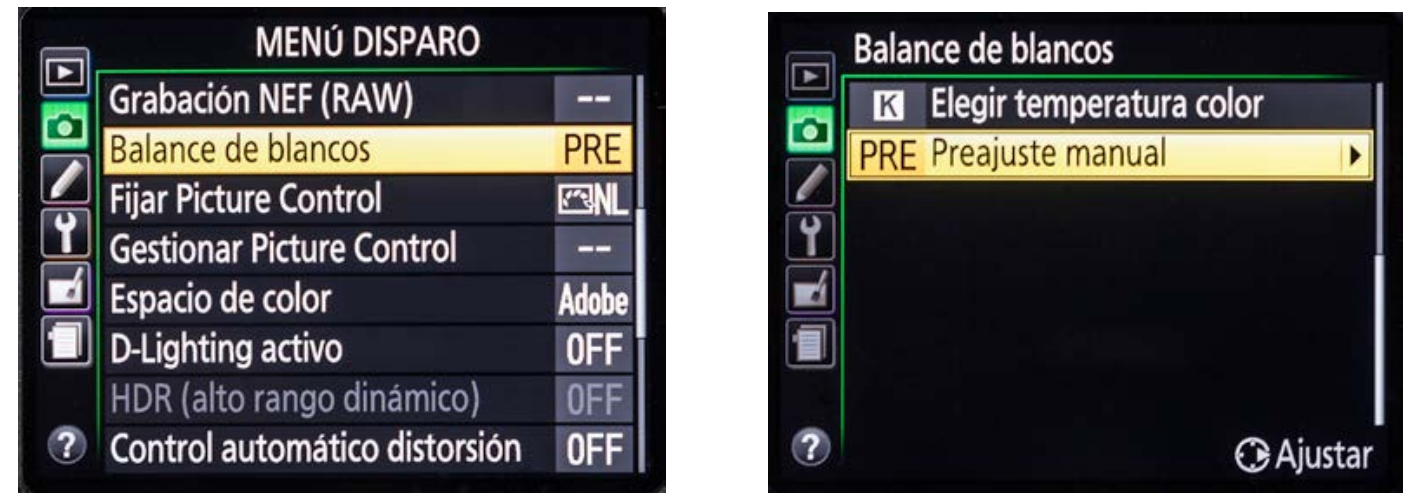

28. Con una cámara Nikon, en el Menú Disparo se selecciona el Balance de blancos PRE. @ Ricardo Guixà

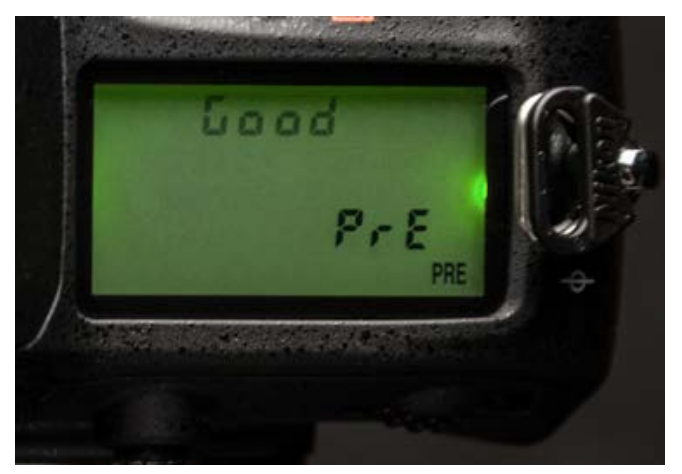

29. Presionar el botón WB (a la izquierda de la pantalla posterior), seleccionar un preajuste (d-I a d-4) soltar y volver a presionar, hasta que parpadee "PRE” en la pantalla superior. (C) Ricardo Guixà

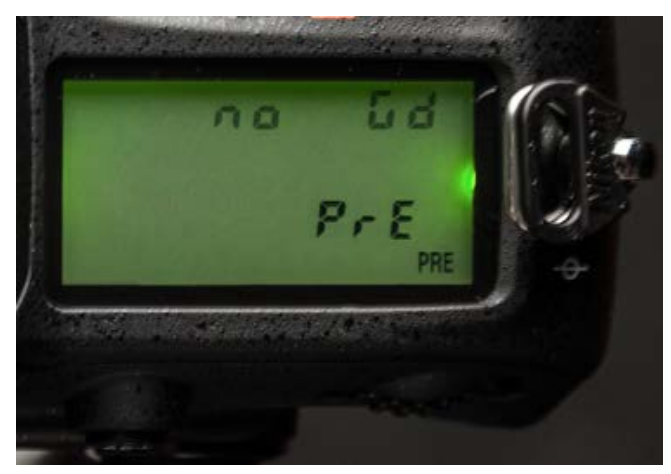

3o. Seguidamente hacer la fotografía del gris medio o del blanco estándar iluminado con la misma fuente de luz que tenga el documento. Si la lectura es correcta, en la pantalla superior aparecerá escrito “Good” y,si no es correcta, “no Gd”. En el segundo caso, hay que repetir el paso anterior (figura 29). @ Ricardo Guixà 
Si se desea conservar esta imagen para utilizarla como muestra posteriormente, hay que hacer otra fotografía y memorizarla asignándole un preajuste. Dependiendo del modelo de cámara, se pueden memorizar hasta seis balances diferentes. Con fuentes de iluminación estandarizadas, como las que se emplean en las mesas de reproducciones, es conveniente guardar una imagen de muestra, para no repetir esta operación al inicio de cada sesión.
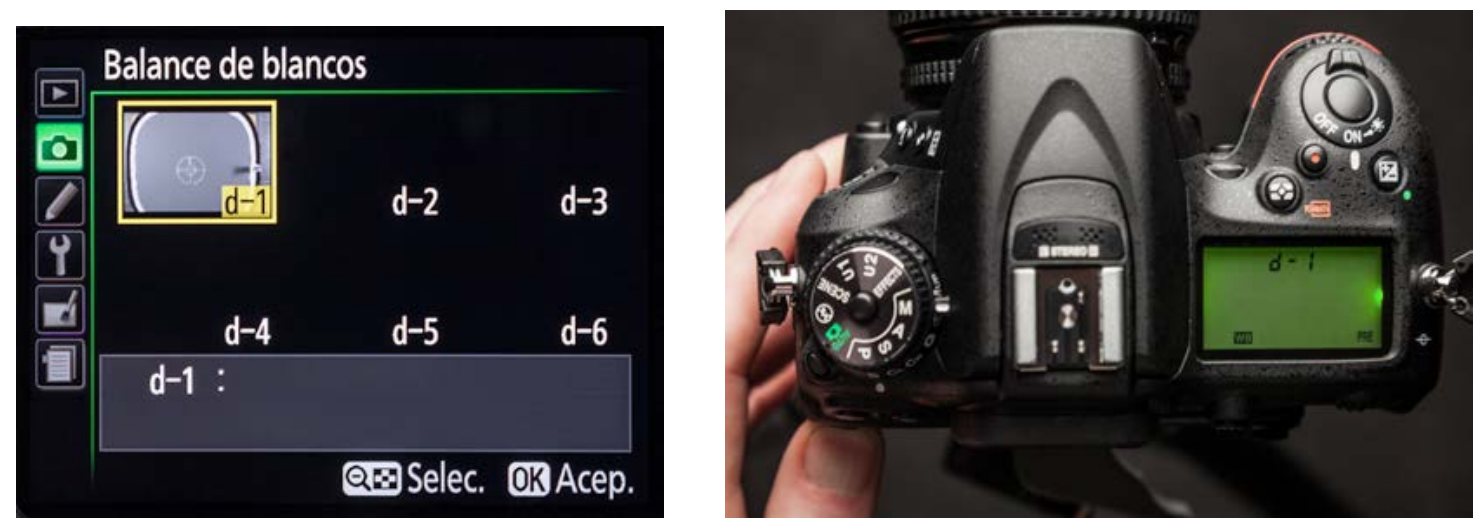

3. Preajuste memorizado d-I en una cámara Nikon D7ıoo. (C) Ricardo Guixà

En todos los procedimientos, después de realizar el ajuste de blancos, se debe retirar la carta gris. Si la fuente de iluminación que empleamos para nuestras sesiones fotográficas es siempre la misma, se puede volver a utilizar la lectura memorizada, aunque hay que tener en cuenta que las lámparas varían su TC con el desgaste provocado por el uso. En el caso de no disponer de tiempo o de una superficie blanca o gris estandarizada, podemos recurrir a otro procedimiento.

$$
\text { 4.2.5.2 Elegir la temperatura de color }
$$

Se va al menú de "Bal. blancos", en el modo "K", y se selecciona la temperatura de color en grados Kelvin que indique el fabricante de las fuentes de iluminación. Posteriormente, hay que elegir ese mismo modo en el ajuste WB. El inconveniente es que no todas las cámaras disponen de este sistema y, cuando lo tienen, no están disponibles todas las TC posibles, teniendo en cuenta que, además, las lámparas cambian de matiz con su utilización y el paso del tiempo, según se ha comentado, por lo que el color inicial tiende a descender. Los led son la única excepción.
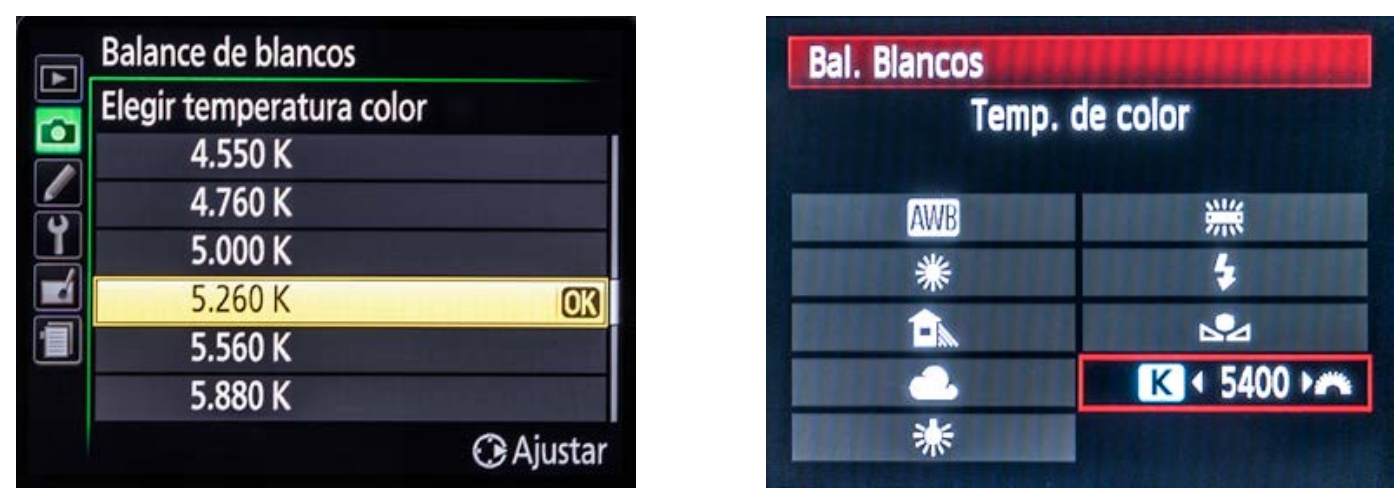

32. Menú de TC en grados Kelvin de cámara Nikon D 7 Ioo (izquierda) y Canon EOS 5 D Mark II (derecha).

(C) Ricardo Guixà 


\subsubsection{Calcular la exposición}

Para esta operación se tienen diferentes opciones, todas las cuales garantizan un resultado correcto, pero con distinto planteamiento. Recomendamos dos.

$$
\text { 4.2.6.I Derecheo del histograma }
$$

Este procedimiento utiliza la información subministrada por el histograma de la fotografía y consiste en situarlo a la derecha para que la zona de luz quede bien expuesta. ${ }^{24}$ Se puede realizar de diferentes maneras. Veamos la más simple, partiendo de los parámetros ya configurados: Modo de exposición M y diafragma dos puntos más cerrado de la máxima apertura ( $f 8$ es una buena referencia, tal y como se ha explicado). El proceso es el siguiente:

I. Activar el LV con el histograma visible.

2. Encuadrar la imagen.

3. Variar el tiempo de obturación hasta que el histograma comience en el lado derecho. Si se quiere asegurar la minimización de las pérdidas de información, se puede añadir un paso más.

4. Hacer la fotografía y visualizar el histograma en RGB de la imagen realizada. En la mayoría de las cámaras que disponen de esta opción, hay que activarla desde el menú de visionado. Si alguno de los tres canales, habitualmente el rojo, está sobreexpuesto, repetir el tercer paso subiendo el tiempo de obturación hasta desplazar el histograma un poco hacia la izquierda (normalmente un tercio o dos tercios de EV es suficiente).
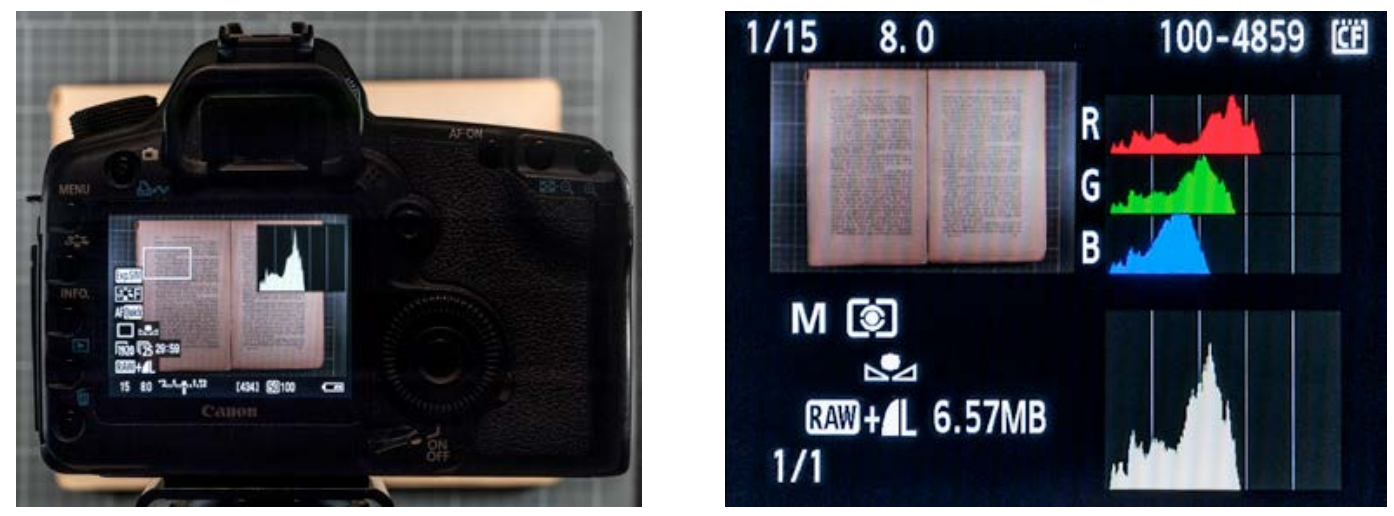

33. Pasos uno y dos . En una cámara Canon EOS ${ }_{5}$ D Mark II, al activar el LV hay que seleccionar con el botón de "Info" el modo de visualización del histograma. Previamente, hay que activar la simulación de la exposición en el menú de herramientas dentro de “Ajust. Func. Visión Dir./Video” en “Aj. Visión Dir”. Con la exposición ajustada a cero, se puede apreciar que el histograma no llega al lado derecho porque el cálculo del fotómetro de la cámara no esta diseñado para una situación como esta. (C) Ricardo Guixà

24. El término derecheo fue acuñado por Michael Reichmann en un tutorial aparecido en la página web Luminouslandscape (http://www.luminous-landscape.com/tutorials/expose-right.shtml). Se basa en la respuesta lineal del sensor digital a la luz y permite mejorar el nivel de ruido de la imagen, así como reducir el efecto de posterización. En función del contraste de la escena, es posible que la imagen visualizada en la pantalla trasera de la cámara tenga un aspecto pálido y con cierta falta de relieve general, y que en el histograma no haya información en la zona de negros y grises oscuros. No hay que preocuparse, porque posteriormente, al editar el RAW, se podrán ajustar las sombras. 

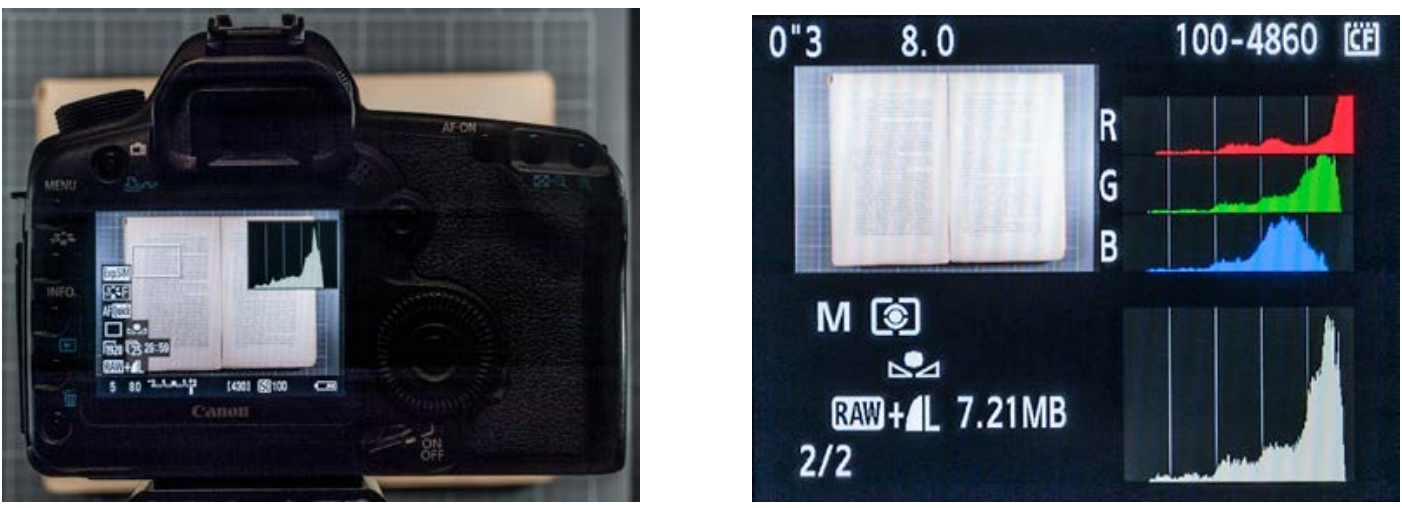

34. En el tercer paso, se corrige la exposición variando el tiempo de obturación, para que entre más luz hasta conseguir que el histograma se sitúe a la derecha de la gráfica. Se hace la fotografía y se comprueban los tres canales. En este caso, el canal rojo está sobreexpuesto, por lo que pierde información. (C) Ricardo Guixà
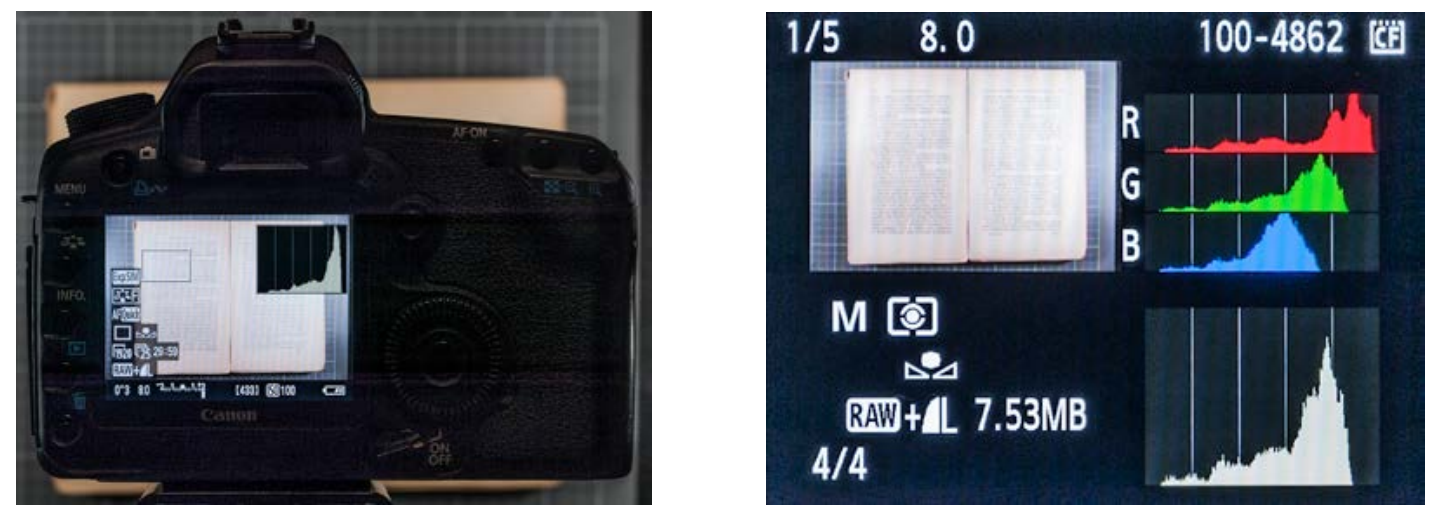

35. En el cuarto paso, si no se quiere perder nada de información en la imagen, se puede proceder a rectificar nuevamente la exposición hasta asegurarse de que no hay ningún canal sobreexpuesto. Nótese que el TO ha pasado de I/I5 a I/5. CRicardo Guixà

En función del contraste de la escena, es frecuente que sea necesario ajustar las sombras en la edición digital de la fotografía, por lo que la imagen que se ve en la pantalla TFT puede quedar clara y con poco contraste, sin que ello signifique que sea incorrecta (vid. nota 24).

Esta primera opción es la más recomendable, si lo que se busca es aprovechar toda la información que es capaz de proporcionar nuestra cámara digital, debido a que más de la mitad de los bits que configuran la fotografía están almacenados en la zona de las luces situada a la derecha del gráfico de barras.

En el caso de que no se disponga de Live View, se puede realizar una fotografía de prueba, visionar el histograma en el modo play de la cámara y rectificar la exposición subiendo o bajando el tiempo de obturación, hasta que las luces queden situadas en la derecha, tal y como se explicó en el cuarto paso.

Existen otras opciones que implican un accesorio independiente de la cámara, entre las que destacaremos solo una, por ser un complemento económico y ligero de transportar.

$$
\text { 4.2.6.2 Medición en carta gris }
$$

Con este procedimiento, se efectúan los siguientes pasos:

I. Situar la carta de grises de tal manera que reciba la misma luz que la escena a fotografiar y 
ocupe la parte central.

2. Seleccionar el modo de medición puntual (spot). En algunos modelos de Canon no está disponible; en tal caso, se elige el modo parcial. Se encuadra procurando que la carta llene toda la superficie del visor o, al menos, el centro del encuadre. Entonces se ajusta el tiempo de obturación hasta que el fotómetro indique una exposición correcta, equilibrada en o. Recuérdese que estamos en modo manual, con un diafragma previamente seleccionado.

3. Una vez realizada la lectura, se retira la carta de grises. Lógicamente, el fotómetro de la cámara indicará una exposición incorrecta, pero no hay que rectificarla.

Reencuadrar la imagen, si es necesario, para ajustarla al documento a fotografiar. No hay problema en mover el anillo del zum o en subir o bajar la cámara posteriormente, porque la combinación del número $f$ y TO no cambia, al estar en modo manual.
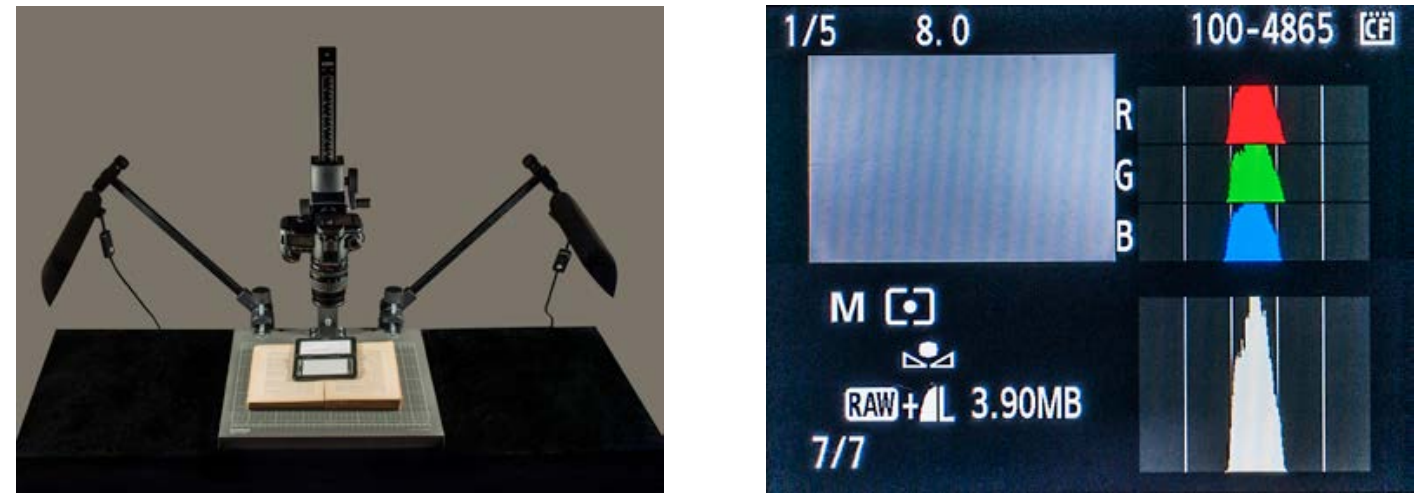

36. Pasos primero y segundo. Si se emplea una carta gris de bolsillo, como la que viene incluida en la tarjeta X-Rite, hay que reencuadrar la imagen para que cubra el visor. En la imagen de referencia obtenida, obsérvese cómo los tres canales tienen exactamente la misma exposición, porque el balance de blancos personalizado hecho anteriormente es correcto. (C) Ricardo Guixà
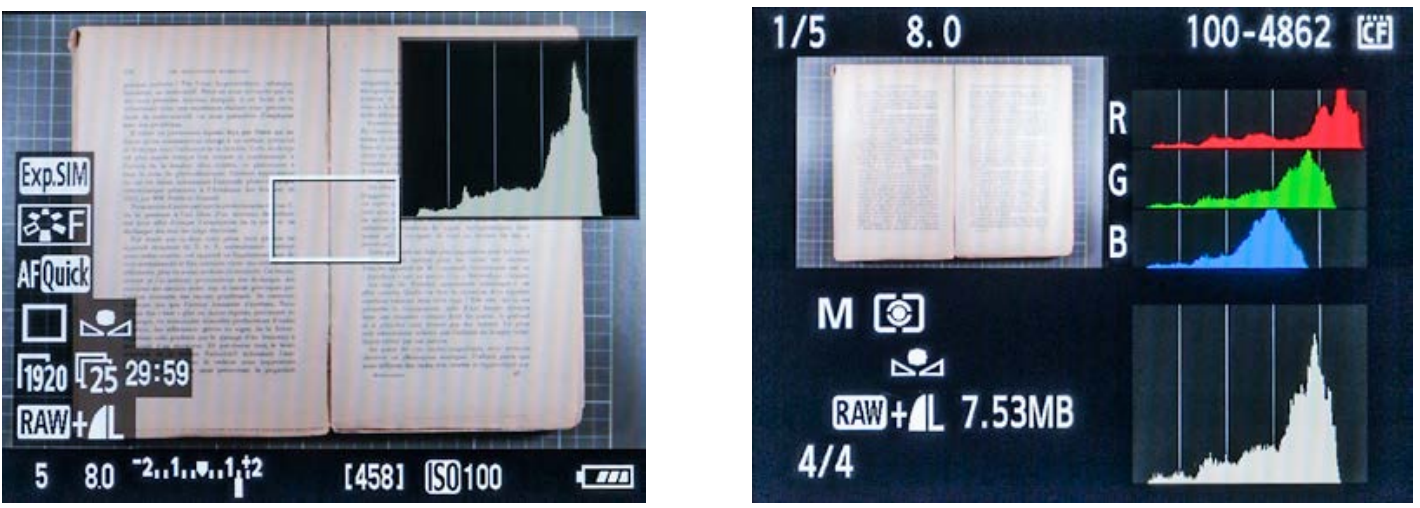

37. En los pasos tercero y cuarto, al apartar la carta gris y ajustar el encuadre al documento, la exposición que indica el fotómetro de la cámara aparece sobreexpuesta un punto y un tercio, pero no hay que rectificarla. En la imagen obtenida no se pierde información en ninguno de los canales, aunque dependiendo del contraste de la escena el resultado puede variar. Afortunadamente, el esquema de iluminación recomendado para reproducir documentos suele tener un bajo contraste. (C) Ricardo Guixà

Con este sistema, la imagen obtenida se ajusta a la percepción que tenemos del objeto y requiere 
menos procesamiento posterior, aunque en ocasiones implica una perdida de bits en las luces de la imagen, en función del contraste de la propia escena. No obstante, si se da esta circunstancia, las perdidas no son apreciables a simple vista para su visionado en la pantalla del ordenador y para las impresiones a tamaños pequeños o medianos, por lo que no perjudican la labor del investigador. Ahora bien, si lo que se busca es la excelencia y la máxima calidad en todas las situaciones posibles, es mejor emplear el primer procedimiento recomendado.

Esta operación se realiza al inicio de la sesión y la lectura sirve para las fotografías posteriores siempre que no cambie la distancia entre la superficie fotografiada y la fuente de iluminación. En el caso de que haya alguna variación de altura, habrá que proceder a tomar una nueva lectura con el mismo método elegido. Por suerte no suele ser necesario para la mayoría de los documentos.

$$
\text { 4.2.7 Fotografiar la carta de color }
$$

Cuando se necesita garantizar una perfecta reproducción del color original, es aconsejable hacer una fotografía con una carta de color situada sobre el motivo fotografiado con la misma iluminación empleada para el documento. Esta imagen servirá de referencia para todo el proceso de gestión de color, que se explicará en próximos artículos. Hay que tener en cuenta que en el estudio de textos no siempre es imprescindible esta exactitud cromática, particularmente cuando la principal finalidad es visibilizar el contenido del escrito. En ese caso, las pequeñas diferencias de matiz que se puedan producir no son significativas para el análisis del filólogo, pero pueden resultar un inconveniente en el trabajo de carácter gráfico documental.

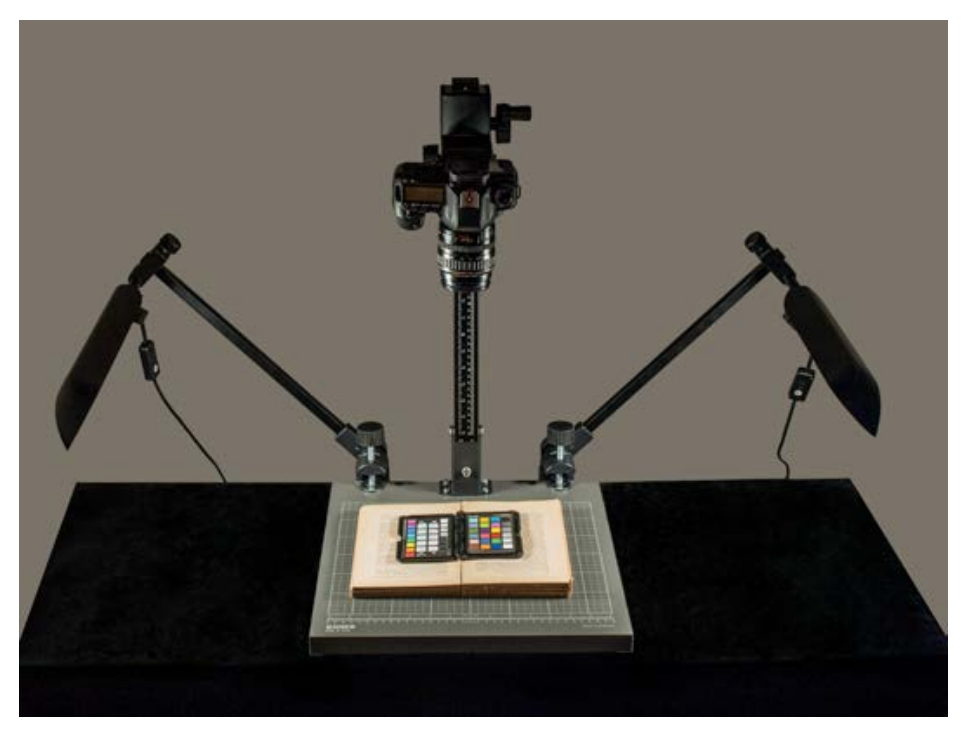

38. La fotografía de referencia con la carta de color se debe hacer con la misma iluminación empleada para el texto y solo es necesario realizar una para toda la sesión, siempre que no cambien las condiciones lumínicas.

(C) Ricardo Guixà

\subsubsection{Toma de la imagen}

Tras realizar estas operaciones, está todo preparado para hacer las fotografías. Los parámetros ajustados se utilizan para la sesión completa, excepto el enfoque, independientemente del encuadre y de la distancia focal seleccionada en la lente, tal y como se ha explicado. Por lo tanto, podemos proceder con los cambios de composición que requieran los textos fotografiados, como subir y bajar la cámara o cambiar el anillo del zum, sin que afecte a la exposición y el WB elegido. 
Mediante este procedimiento se garantiza una reproducción fotográfica del documento estudiado de carácter científico, fiel al original, optimizando al máximo la información suministrada por la imagen capaz de cumplir las necesidades del más exigente de los investigadores. ${ }^{25}$

\section{Protocolo en condiciones de precariedad de medios}

Como sabe todo filólogo experimentado en el trabajo de campo, desgraciadamente no siempre se dan las condiciones ideales planteadas en este artículo. En ocasiones no es posible disponer de un trípode y mucho menos de una mesa de reproducciones, por razones variadas. Además hay bibliotecas en la que no se permite el acceso con un equipo tan aparatoso. En estas circunstancias, la obtención de fotografías de calidad se convierte en una tarea complicada y hay que adaptarse a los medios de que se dispone, con la luz existente en el lugar y un disparo a pulso, a costa de sacrificar calidad de imagen.

Dada esta situación de precariedad, hay que tratar de optimizar los recursos para que la merma de información sea la mínima posible. En esencia, la configuración de la cámara y el proceso de trabajo son los mismo, pero con algunas variables importantes sobre el base propuesta.

\section{I Configuración de la cámara}

ISO: Entre 400 y i6oo, el más bajo posible que nos permita la luz del lugar, pero vigilando que el tiempo de obturación no sea excesivamente lento.

Modo de disparo: Único, en Canon, S en Nikon, si el tiempo de obturación está por encima de I/3o de segundo. Para tiempos más lentos, es preferible utilizar el disparo en ráfaga, CL o CH en Nikon, "disparo en serie” para Canon. Más adelante se explica el porqué de esta elección.

Modo de exposición: Manual M.

No $f$ : Cerrar dos puntos por encima de la máxima apertura sigue siendo una buena opción; pero si la luz es escasa y los tiempos resultan excesivamente lentos, será necesario abrir el diafragma todo lo posible. El tiempo de obturación vendrá igualmente determinado por la medición del exposímetro incorporado.

Enfoque: Manual o automático, según la dificultad de su control en función del procedimiento.

Estabilizador de imagen: Activado.

El resto de los parámetros son iguales que en el protocolo anterior.

\subsection{Proceso de trabajo}

I. Ajustar los parámetros de cámara recomendados.

2. Preparar el documento a fotografiar e iluminar. Dentro de la disponibilidad del lugar, buscar

25. Para entender en profundidad la dimensión documental de los productos de la cámara desde un punto de vista historiográfico es recomendable el libro de Beatriz de las Heras (2OI2). Se trata de un interesante análisis de la fotografía como elemento del conocimiento científico a lo largo de la historia del medio, en el que se analizan todos los elementos que intervienen en el fenómeno fotográfico y que deben ser tenidos en cuenta por el historiador ante el análisis de las imágenes fotográficas. 
una fuente de iluminación de la mayor intensidad posible. Si es luz natural, se ha de procurar que no cree reflejos en la superficie del escrito desde el punto de vista de la cámara. Si son flexos o similar, situarlos a los lados en un ángulo aproximado de $45^{\circ}$. No utilizar nunca el flash incorporado a la cámara, dado que el ángulo de incidencia de los rayos luminosos provocaría inevitablemente una reflexión directa que causaría interferencia en la legibilidad del texto. Si sólo se pueden emplear las lámparas del techo, hay que proceder de la misma manera que con la luz natural. Se recomienda no mezclar luces de diferente calidad cromática, por ejemplo fluorescentes con halógenos o luz natural, siempre que las circunstancias lo permitan.

3. Realizar el balance de blancos. Se empleará el mismo procedimiento descrito anteriormente, dando preferencia al WB personalizado, porque la lámparas que se utilizan habitualmente para iluminar las bibliotecas tienen una TC que no está dentro de los estándares de la fotografía. Si hubiera dos fuentes de distinto color, hay que hacer el balance con la luz dominante. Inevitablemente habrá una pequeña desviación de matiz en la imagen que, por lo general, no será un problema grave para el análisis del texto y, por tanto, representa un mal menor asumible.

4. Calcular la exposición derecheando el histograma o sobre la carta gris, tal y como se ha explicado. Si la intensidad luminosa es escasa, será necesario incrementar el valor ISO. Normalmente, en las modernas cámaras digitales el ruido electrónico está bastante bien controlado hasta los 400 ISO. Por encima de esta cifra, depende mucho del modelo empleado. Lógicamente, las cámaras de gama alta y las más actuales proporcionan niveles más bajos de interferencia, aunque con guarismos superiores a i6oo la pérdida de calidad es claramente visible. En estas circunstancias, será necesario abrir el diafragma a la máxima apertura, con la inevitable pérdida de profundidad de campo que conlleva, por lo que será imprescindible afinar en el enfoque del texto.

A partir de estos parámetros el fotómetro nos proporcionará el tiempo de obturación. El inconveniente en estas circunstancias de luz precaria es que hay una alta posibilidad de que sea excesivamente lento para disparar a pulso sin que la imagen quede trepidada. Por muy bien que se sujete la cámara, es absolutamente inevitable que haya cierta oscilación en diferentes ángulos y direcciones.

El tiempo límite para obtener un resultado aceptable depende de dos factores: el pulso de quien hace la fotografía y la distancia focal al objetivo empleado. El primero es intrínseco de cada persona y difícilmente lo podremos mejorar. El segundo es una variable que está directamente relacionado con el tamaño de los fotositos del sensor. Cuanto más pequeños sean, más evidente será el desplazamiento de la cámara.

Existe una regla que permite hacerse una idea aproximada del tiempo mínimo que podemos emplear con ciertas garantías. Con una focal de $30 \mathrm{~mm}$ hay que disparar a I/30; con $50 \mathrm{~mm}$, a I/5o (o I/6o); con 500 mm, a I/5oo de segundo, y así sucesivamente. Teniendo en cuenta que las DF para la fotografía de documentos suelen oscilar entre 30 y $80 \mathrm{~mm}$, para una cámara APS-C, y entre 40 y Ioo mm para las FF, el rango de tiempos aconsejables variará entre I/3O y un I/ I25 de segundo o superiores.

Hay que considerar que a veces una foto ligeramente movida puede darse por buena si no se necesita ampliar mucho o mirarla al ıoo\% de su tamaño en la pantalla del ordenador. Si la trepidación es muy leve, no se verá movida, sino algo menos nítida.

$\mathrm{Si}$, a pesar de todo, el tiempo es inferior a I/3o de segundo, podemos seleccionar en la cámara el modo de disparo en ráfaga, y después hacer una serie de fotos (entre 6 y Io es suficiente) de la forma explicada en el párrafo anterior, sin soltar el disparador, con el AF 
desconectado y procurando aguantar la respiración durante la toma. Se verá que algunas de las fotografías están mucho menos movidas que las otras e incluso alguna puede llegar a ser perfecta. Al hacer más tomas de la misma escena, estadísticamente hay más posibilidades de que una de ellas haya coincidido con un momento de relativa quietud en nuestra inevitable oscilación.

Activación del estabilizador de imagen. Actualmente, muchos equipos fotográficos disponen de un sistema de estabilización de la cámara que amortigua los movimientos provocados por el pulso. Pueden ser de dos tipos:

I. El estabilizador óptico, montado en los objetivos y adoptado por Nikon, Canon, Panasonic y Leica (llamados VR, IS y MegaIOS respectivamente). Al estar optimizado para cada lente, suele proporcionar un buen rendimiento.

2. El estabilizador mecánico, instalado en el cuerpo de la cámara y empleado por Olympus y Sony. Tiene la ventaja evidente de que todas las ópticas que pongamos a ese cuerpo estarán estabilizadas, sin ningún coste adicional para cada una de ellas. Si bien parece que el rendimiento es algo menor que el del anterior sistema, también resulta un método efectivo, que se traduce en la posibilidad de disparar con uno, dos o tres puntos de obturación más lentos sin vibración aparente en la imagen, dependiendo de la calidad del sistema.

Si las condiciones de luz no varían, se pueden emplear los parámetros calculados para toda la sesión. Con la luz natural es conveniente realizar un ajuste del WB y del TO a medida que vaya cambiando a lo largo de su transcurso aparente por la bóveda celeste.

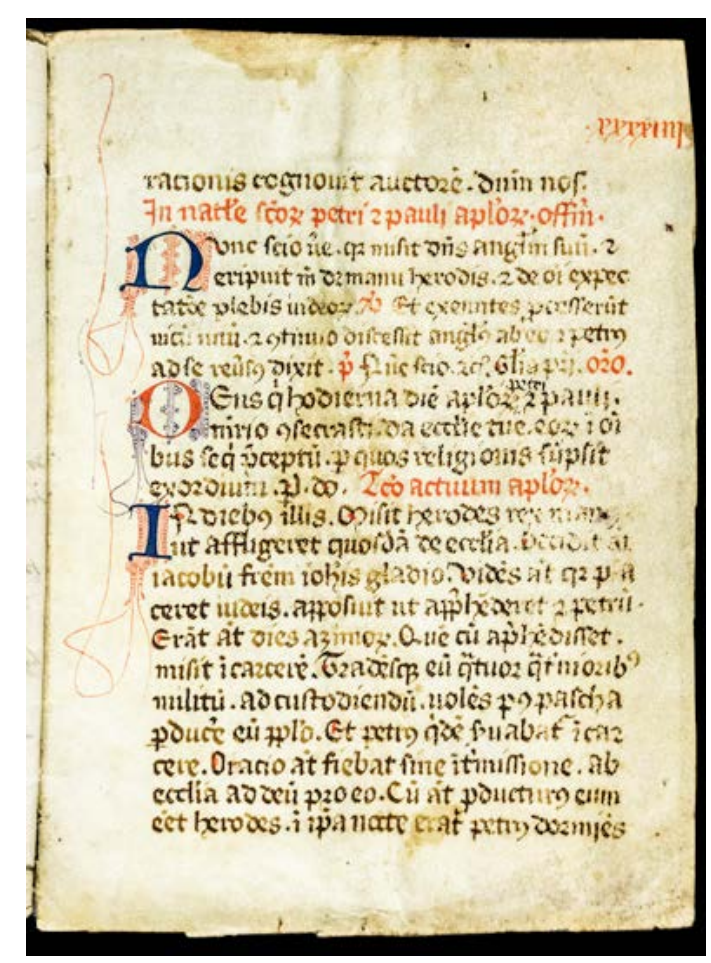

39. Codex Villarensis, Biblioteca de la Universidad de Zaragoza, ms. 225, olim 4I, f. 44r (C) Biblioteca de la Universidad de Zaragoza). Fotografía realizada por Ricardo Guixà en las instalaciones de la biblioteca, siguiendo el protocolo descrito en estas páginas, mediante una cámara Canon EOS 5 D Mark II sujeta a una mesa de reproducción. 


\section{Anexos}

\section{I Glosario}

Aberración de distorsión: Se trata de un defecto de las lentes caracterizado por la deformación de la imagen en sus extremos, hinchándose (barrilete) o encogiéndose (cojín), dependiendo del diseño del objetivo utilizado.

Aberración cromática: Es la incapacidad de una lente para enfocar a la misma distancia las diferentes frecuencias de onda (colores) que forman la imagen. En una fotografía produce un halo amarilloazul o verde-magenta en los contornos más contrastados.

Aberración esférica: Constituye la incapacidad de una lente para enfocar a la misma distancia los rayos más próximos y alejados del eje óptico. Es decir, la lente tiene una forma curvada, por lo que proporciona una imagen igualmente curva, pero la superficie del sensor digital es plana por lo que el plano de enfoque varía entre el centro de la imagen y los extremos. Se corrige añadiendo elementos ópticos asféricos o anasféricos.

Balance de Blancos (WB): Es un ajuste electrónico de la cámara que permite equilibrar los tres canales, rojo, verde y azul (RGB), que componen la fotografía, para corregir las posibles dominantes de color de una fuente de iluminación.

Adobe RGB: Espacio de color diseñado por la empresa Adobe caracterizado por tener una gama tonal más amplia que el estándar s-RGB.

APS: Formato de fotografía digital que se aplica a sensores del tipo CMOS con un tamaño aproximado $23,5^{\times}$I5,5 $\mathrm{mm}$ (que varía según la cámara) y una proporción 3:2, la misma que la película de formato pequeño de $35 \mathrm{~mm}$. Es el habitual en las cámaras réflex digitales de gama baja o media y tiene diferentes versiones, siendo la C (Classic) la más común.

Distancia hiperfocal: Es la distancia de enfoque que permite aprovechar al máximo la profundidad de campo que proporciona cada objetivo. Se calcula enfocando a un punto intermedio entre el primer y el último plano de la imagen que queremos que se vea nítido. Aproximadamente está situado un tercio por detrás del plano más cercano que necesitamos que salga definido.

Distancia focal: Es la distancia entre el plano nodal de la lente y el plano focal; es decir, la distancia entre el centro óptico del objetivo y el plano en el que se proyecta la imagen nítida. En función del tamaño del sensor, determina el ángulo de visión de la lente.

Fotosito: Es cada uno de los fotodiodos sensible a la luz que componen la superficie del sensor digital de una cámara. Su tamaño depende de la densidad de integración del chip y del tamaño del sensor. Cuanto más pequeños son los fotositos, mayor ruido digital se genera.

Full Frame of formato completo: Es la denominación que reciben los sensores digitales cuyo tamaño es igual al fotograma de la película de formato pequeño, esto es, $36 \times 24 \mathrm{~mm}$.

Histograma: El histograma de una fotografía digital es la representación gráfica de los doscientos cincuenta y seis niveles de luminosidad que compone cada canal de 8 bits de la imagen en una variable en forma de barras. Constituye una herramienta imprescindible para ajustar correctamente la exposición. En la zona derecha están representadas las luces de la fotografía, es decir los blancos y grises claros. En el centro se encuentran los grises intermedios y a la izquierda los grises oscuros y negros, que corresponden a las sombras de la imagen.

ISO: Normativa producida por la International Organization for Standardization para tipificar 
muy diversas materias y que en fotografía se aplica, por antonomasia, a la norma que regula la sensibilidad a la luz de los materiales fotosensibles mediante una escala numérica en la que, partiendo de Ioo, cada valor es el doble que el anterior y la mitad que el siguiente. Así una cámara ajustada con un ISO 200, por ejemplo, necesita el doble de exposición, bajo las mismas condiciones, que un ISO 400.

$J P E G$ : En el terreno específico de la fotografía, se trata de un formato de archivo y codificación de imágenes estándar. Emplea un algoritmo matemático que elimina la información redundante de la fotografía comprimiéndola para que disminuya de tamaño. Al volver a abrir el archivo, este se descomprime, recuperando la información original o parte de ella. Tiene diferentes niveles de compresión que en el menú de la cámara vienen indicados mediante dos características diferenciadas: tamaño de la imagen y calidad. Cada marca muestra las diferentes opciones de distinta manera. A mayor tamaño y calidad, menor compresión de datos, por lo que los valores más altos no producen perdida de información.

Live view o visionado de la imagen en directo: Es una tecnología que permite ver en la pantalla LCD de la cámara y en tiempo real la escena encuadrada por el objetivo.

Posterización: Efecto fotográfico que imita el acabado con tintas planas de los carteles pintados a mano. También se aplica a la pérdida de información provocada por algunos procesos en la edición de la imagen digital, la cual tiene como resultado la conversión del degradado de tono continuo propio de la fotografía en cambios bruscos de tono claramente diferenciados.

Profundidad de campo: Es la distancia que hay entre el plano más cercano y más alejado de la cámara que se ve nítido sin tener que mover el anillo de enfoque. Depende de tres factores: la distancia focal del objetivo, cuanto más larga, menor PC; la distancia entre la cámara y el plano enfocado, cuanto más cercana, menor PC, y la apertura del diafragma, cuanto más abierto (números $f$ más bajos), menor PC.

Rango dinámico: El rango dinámico de un dispositivo, ya sea de captura o de reproducción, es la diferencia entre la frecuencia más alta y la frecuencia más baja que es capaz de captar, emitir o transmitir de forma simultánea. En términos fotográficos, se refiere a la capacidad del sensor para reproducir diferencias de contraste entre las partes más claras y las más oscuras de la imagen de las cuales queremos conservar el detalle visible de su volumen y superficie.

$R A W$ ('en bruto' o 'en crudo'): Formato fotográfico cuyos datos se toman de la memoria intermedia de la cámara antes de ser procesados. Está destinado a captar lo mejor posible (optimizando las capacidades de un sensor dado) las características radiométricas de la escena, es decir, la información física acerca de la intensidad de la luz y el color de la misma.

Ruido: El ruido digital en fotografía es una interferencia electrónica provocada por el propio funcionamiento del sensor. Existen dos tipos: el ruido de luminancia, que se aprecia como píxeles de tono más claro o más oscuro, y el ruido de color, que se manifiesta de la misma forma, pero además cambiando de color. El ruido se incrementa al subir el ISO, con los tiempos de exposición largos y con el calor.

Sensor digital: Es un chip electrónico compuesto por una matriz de elementos fotosensibles (píxeles) situado en el plano focal de la cámara sobre el que se proyecta la imagen del objetivo.

SLR: Denominación abreviada para las cámaras réflex de un objetivo.

Temperatura de color: Es una expresión que se refiere a la distribución espectral de la energía de una fuente luminosa. Se utiliza para especificar su color tomando como referencia la temperatura en 
grados Kelvin a la que es emitido dicho color por un objeto metálico negro al ser calentado. Así, por ejemplo, el color blanco tienen una TC de $5500 \mathrm{~K}$ y el rojo de I80o K.

TIFF: Formato estándar de imagen digital, con o sin compresión, que garantiza una gran calidad de la fotografía, al constar de un mayor peso del archivo.

Zum o Zoom: Es un objetivo caracterizado por tener la distancia focal variable, que permite cambiar el ángulo de visión sin tener que desmontar la óptica de la cámara.

\title{
6.2 Acrónimos
}

\author{
AF: Auto Focus \\ APS-C: Advanced Photo System-Classic \\ CSC: Compact System Camera \\ DF: Distancia Focal \\ EV: Exposure Value \\ EVIL: Electronic Viewfinder with Interchangable Lens \\ FF: Full Frame \\ HMI: Hydrargyrum Medium-arc Iodide \\ IS: Image Stabilizer \\ JPEG: Joint Photographic Experts Group \\ LV: Live View \\ MF: Manual Focus \\ PC: Profundidad de Campo \\ RGB: Red, Green, Blue \\ SLR: Sigle Lens Reflex \\ TC: Temperatura de Color \\ TO: Tiempo de Obturación \\ TIFF: Tagged Image File Format \\ TFT: Thin-Film Transistor \\ VR: Vibration Reduction \\ WB: White Balance
}

\section{${ }_{7}$ Obras citadas}

Bücheler, Franz, ed., I895-I897, Anthologia latina sive Poesis latinae Supplementum, Pars posterior: Carmina epigraphica, Fasciculi I et II: Carmina latina epigraphica, Leipzig, B. G. Teubner (Bibliotheca scriptorum Graecorum et Romanorum Teubneriana), 2 vols..

Atkins, Bob, 2OIO, White balance and color temperature made simple. http://tinyurl.com/pbqvete (checked 3-o8-2013).

Binkley, Robert C., I93I. Methods of reproducing research materials: a survey made for the Joint Committee on Materials for Research of the Social Science Research Council and the American 
Council of Learned Societies, Ann Arbor (Mich.), Edwards. http://tinyurl.com/olsjfoy (checked I5-O3-2013).

Chirollet, Jean-Claude, 2005, Numériser, reproduire, archiver les images d'art, Paris, L'Harmattan.

Faraggiana di Sarzana, Chiara, 2003, "La fotografia applicata a manoscritti di difficile lettura: origini ed evoluzione di uno strumento di ricerca e i principi che ne regolano l'uso", en $E l$ palimpsesto grecolatino como fenómeno librario y textual, Ángel Escobar ed., Zaragoza, Institución Fernando el Católico, 2006, 65-80.

Faraggiana di Sarzana, Chiara, 2007, "Leggere manoscritti nell'era digitale: nuove prospettive e vecchi problemi”, en From manuscript to digital text: Problems of interpretation and markup, Roma, Herder (Papers on Grammar, IX 3), 35-6o.

García Efraín; Osuna Rubén, 2OII, Fundamentos de fotografía digital, Madrid, UNED. http:// tinyurl.com/ngf3z63 (checked 2O-O7-2OI3).

Heras, Beatriz de las, 2012, El testimonio de las imágenes: fotografía e historia, Madrid, Creaciones Vincent Gabrielle.

Koren, Norman, 20I3, Digital cameras vs. film. http://tinyurl.com/j6I3 (checked 23-05-20I3).

Langford, Michael, r998, Tratado de fotografia, Barcelona, Omega.

Leclerc, Michael J., 20IO, 'Research recommendations: Scanning vs. photographing”, NEHGS eNews I3(32), II-O8-2OIO. http:// tinyurl.com/q7yqwmq (checked 2I-O2-2OI4).

Le Guillou, Yves, 2008, La reproduction des documents graphiques: Usages et enjeux, París, Editions L'Harmattan.

McHugh, Sean, 2013, "Digital camera sensor sizes", en Cambridge in Colour. http://tinyurl.com/ ah7nc (checked 23-O5-20I3).

Merklinger, Harold M., 2002, The INs and OUTS of FOCUS: An alternative way to estimate depthof-field and sharpness in the photographic image, Dartmouth, Technical Books on Photography. http://tinyurl.com/nboq7be (checked 8-o8-20I3).

Montaner, Alberto, 2008, “The medievalist's gadget: hyperspectral photography and the phantom scribe”, Ecdotica 5, 359-75.

Montaner, Alberto, 2009, "La fotografía hiperespectral y la restauración virtual de códices medievales: aplicación al manuscrito único del Cantar de mio Cid’ en Los códices literarios de la Edad Media: interpretación, historia, técnicas y catalogación, Eva Belén Carro Carbajal, Javier Durán Barceló, Pedro M. Cátedra ed., San Millán de la Cogolla, Instituto de Historia del Libro y de la Lectura (CiLengua), 26I-8I.

Reichmann, Michael, 2003, "Maximizing $\mathrm{S} / \mathrm{N}$ ratio in digital photography", en The luminous landscape. http://tinyurl.com/2hebo (checked 20-O7-20I3).

Rodney, Andrew, 2005, Color management for photographers, Oxford, Focal Press.

Rodríguez, Hugo, 20II, Captura digital y revelado RAW, Barcelona, Marcombo.

Westfall, Chuck, 2006, "Effect of IS on projected image... Replay \# 4", en The luminous landscape. http://tinyurl.com/ptgqdkq (checked o6-o9-20I3).

Weston, Chris, 2008, Domina la exposición digital, Barcelona, Index Books. 